UNIVERSIDADE DE SÃO PAULO

HOSPITAL DE REABILITAÇÃO DE ANOMALIAS CRANIOFACIAIS

BEETHOVEN ESTEVAO COSTA

Avaliação e comparação de programas de mensuração do volume do espaço aéreo e da área axial mínima em pacientes com fissura labiopalatina 



\title{
Avaliação e comparação de programas de mensuração do volume do espaço aéreo e da área axial mínima em pacientes com fissura labiopalatina
}

\author{
Dissertação apresentada ao Hospital de \\ Reabilitação de Anomalias Craniofaciais \\ da Universidade de São para obtenção do \\ título de Mestre em Ciências da \\ Reabilitação, na área de concentração \\ Fissuras Orofaciais e Anomalias \\ Relacionadas.
}

Orientadora: Profa ${ }^{\text {. Dr }}{ }^{\mathrm{a}}$ Simone Soares

\section{Versão Corrigida}


Costa, Beethoven

Avaliação e comparação de programas de mensuração do volume do espaço aéreo e da área axial mínima em pacientes com fissura labiopalatina / Beethoven Estevao Costa. -- Bauru, 2021.

70 p. : il. ; $31 \mathrm{~cm}$.

Dissertação (mestrado) -- Hospital de Reabilitação de Anomalias Craniofaciais, Universidade de São Paulo, 2021.

Orientadora: Prof $^{\mathrm{a}} \mathrm{Dr}^{\mathrm{a}}$. Simone Soares

Nota: A versão original desta dissertação encontra-se disponível no Serviço de Biblioteca e Documentação da Faculdade de Odontologia de Bauru - FOB/USP.

Autorizo, exclusivamente para fins acadêmicos e científicos, a reprodução total ou parcial desta dissertação/tese, por processos fotocopiadores e outros meios eletrônicos.

Assinatura:

Data: $14 / 07 / 2021$

Comitê de Ética do HRAC-USP

Protocolo $n^{\circ}: n^{\circ} 3.605 .233$

Data: 27 de setembro de 2019 
ERRATA 

FOLHA DE APROVAÇÃO 



\section{DEDICATÓRIA}

Dedico este trabalho ao meu querido bisavô, senhor Francisco Luiz Batista (in memorian), um homem de caráter inestimável, o qual me incentivou sempre a fazer o melhor e participou em muito na minha educação e formação como pessoa. Suas histórias e conselhos ainda vagam pelas minhas lembranças, sendo um incentivo a sempre lutar com determinação, garra e amor. 



\section{AGRADECIMENTOS}

A Deus por me abençoar e iluminar em todos os momentos da minha vida, tudo que sou é graças a Ele. Em todos momentos de angústia e aflição, Ele veio ao meu encontro e me socorreu.

A minha esposa e companheira de vida Vanessa Abreu Sanchez Marques Costa pelo carinho, dedicação, companheirismo e amor. Com certeza sua dedicação e compromisso com a ciência sempre me motivaram a melhorar profissionalmente. Te amo muito.

Aos meus pais Eduardo Costa e Magda Costa, exemplos de superação, determinação, amor incondicional e por sempre me conduzirem no caminho certo. Obrigado por mostrar que a vida é guiada pelos nosso Criador e Salvador Jesus Cristo, sem vocês para me mostrarem o caminho santo e verdadeiro, eu jamais teria sequer almejado esta vitória, que Deus possa estar sempre em meu coração.

Ao meu querido irmão Filipe Eduardo Costa, pelo companheirismo, amizade e amor. Você sem dúvidas é um garoto muito especial, e pode ter certeza que sempre te apoiarei em tudo.

Aos meus avós Francisco Luís Da Costa e Nilza Antunes da Costa, por todo apoio, amor e orações, suas orações me guiaram nos dias difíceis que tive em Bauru. A minha querida avó Maria da Conceição Ferreira (in memorian), mulher de fibra, de garra e com um enorme coração, cheio de amor e caridade, a qual sempre foi exemplo de superação e determinação. A senhora sempre estará em meu coração, mesmo com Alzheimer tenho certeza que a senhora ainda quer nosso melhor.

A todos meus familiares em Minas Gerais, que mesmo distante ainda querem o meu melhor.

A minha sogra Jeovanete França Abreu Marques e minha cunhada Erika Abreu Sanches Marques por me acolherem em seus lares, me mostrando o quão grande podemos ser bondosos e carinhosos para com o próximo.

A minha orientadora Profa. A Dra. Simone Soares o qual tive o imenso prazer em conhecer. Seu carisma, inteligência, bom humor e paixão pela ciência são verdadeiramente motivadores. 

Ao meu co orientador Prof. Dr. Renato Yassutaka Faria Yaedú pela rica e grandiosa oportunidade no desenvolvimento de tal pesquisa. Professor Renato sempre diz que é difícil ser um grande cirurgião e um bom professor, mas devo confessar que na figura dele percebi a essência do ser professor e a habilidade nata do bom cirurgião.

A minha nova família em Bauru (Luciana, João, Guilherme e Henrique). A meus novos 'avós' que tive o prazer de conhecer em Bauru (Nilton Gulinelli, Neusa Gulinelli e todos seus genros, nora, filhos, filhas e netos), vocês são parte da minha vida, e agradeço muito a Deus pela oportunidade de conhecer a todos, meu muito obrigado por todos momentos.

Aos mestres e grandes amigos, Ms Guilherme Alves Oliveira, Dr. Gabriel Cury, Ms. José Laurenti por fornecerem sempre palavras de apoio e incentivo ao longo desta jornada, em especial meu grande amigo Ms. Nicolau Babadopulos, que sempre foi um apoiador e muita das vezes um pai na cidade de Bauru, ser humano de alma pura, enorme coração, o qual devo meu sincero e eterno obrigado.

Aos meus amigos em Bauru, Prof. O Dr. Rorberto Kawakami, Dr Pedro Amorim, Dr. Leopoldo Aguiar,

A minha madrinha de casamento Leticia Citelli Conti, profissional em excelência, seu exemplo é motivador.

Aos meus professores em Bauru, Prof. O Dr. Paulo Domingos Ribeiro Júnior, Prof. Dr. Luis Eduardo Marques Padovan, Prof. O Dr. Hugo Nary Filho, Profa. Dra. Ivete Aparecida de Mattias Sartori, por todo apoio e incentivo na docência.

Aos meus eternos mestres Dra. Flavia Isabela Barbosa, Ms. Verediano Silveira, Dr. Frank Ferreira Silveira, vocês são a vitrine de ética, profissionalismo e conhecimento em que me espelho para ser um profissional e uma pessoa melhor. Em especial ao meu querido professor, mestre e amigo Dr. Wilson Batista Mendes, um ser humano de inestimável valor, reconhecido não somente pelo seu profissionalismo, mas também pelo seu lado humano e de caráter incalculável.

Aos meus eternos amigos, conselheiros, apoiadores Gabriel Duarte e Nataira Momesso, os quais devo todo o meu respeito, carinho e cordialidade, sem vocês com certeza eu não conseguiria, obrigado pelo imensurável apoio e incentivo. 

Ao Hospital de Reabilitação de Anomalias Craniofaciais da Universidade de São Paulo (HRAC-USP), na pessoa de seu superintendente Prof. O Dr. Carlos Ferreira dos Santos.

A Pós-graduação do HRAC/USP, coordenação, profissionais e professores que tive a honra e o prazer de conhecer e conviver.

Aos profissionais do setor de Cirurgia Ortognática do HRAC/USP, pelo acolhimento e cumplicidade durante a realização dessa pesquisa, por sempre esclarecerem minhas dúvidas e estarem disponíveis para aconselhar em qualquer dificuldade encontrada.

À Coordenação de Aperfeiçoamento Pessoal de Nível Superior (CAPES), pelo apoio financeiro e concessão da bolsa de mestrado para execução deste trabalho. 

AGRADECIMENTO ESPECIAL

À minha orientadora,

Profa. A Dra. Simone Soares

Ao pesquisador colaborador,

Prof. O Dr. Renato Yassukata Faria Yaedu 

"Faça o teu melhor, na condição que você tem, enquanto você não tem condições melhores, para fazer melhor ainda!".

Mario Sergio Cortella 



\section{RESUMO}

Devido ao crescente uso da tomografia computadorizada tipo feixe cônico (TCFC), aumentou-se a busca por softwares para arquivos DICOM que permitem a avaliação e a mensuração da área craniofacial. O objetivo deste trabalho foi comparar a medida do volume do espaço aéreo e a menor área axial da via aérea em pacientes com fissura labiopalatina por meio de 5 diferentes softwares de imagem: Dolphin3D, InVivo Dental, ITK Snap, InVesalius e NemoFAB, para análise tridimensional da via aérea, através de imagens de TCFC. Inicialmente, um examinador selecionou através de randomização 100 TCFC de um arquivo de 450 TCFC, sendo coletado seu arquivo DICOM. As segmentações da orofaringe foram realizadas de acordo com as referências do fabricante, com duas técnicas para segmentação: intervalo de limiar interativo e intervalo de limiar fixo. Os resultados foram submetidos a um teste de análise de variância (ANOVA) sendo adotado um nível de significância de $5 \%$ para todos os testes estatísticos. Os resultados encontrados tanto para análise da área seccional mínima quanto o volume total mostraram que os valores medianos entre os grupos de tratamento são maiores do que seria esperado e quando houve comparação entre cada grupo existiu diferença estatisticamente significante $(P=$ $<0,001)$. Nos resultados da área mínima axial, todos os cinco programas apresentaram diferenças estatísticas significativas entre si. Com relação ao volume, houve diferença estatística significativa também em todos os grupos, exceto entre o software in VIVO e ITK-Snap (para esta análise).

Palavras-chave: Processamento de Imagem Assistida por Computador. Imageamento Tridimensional. Manuseio das Vias Aéreas. Remodelação das Vias Aéreas. 



\section{ABSTRACT \\ Comparison of the minimum sectional area and volume in patients with cleft lip and palate using different imaging software}

Due to the increasing use of cone beam computed tomography (CBCT), the search for software for DICOM files that allows the evaluation and measurement of the craniofacial area has been increased. The aim of this study was to compare the measurement of airspace volume and the smallest axial area of the airway in patients with cleft lip and palate using 5 different imaging software: Dolphin3D, InVivo Dental, ITK Snap, InVesalius and NemoFAB, for three-dimensional analysis of the airway aerial view, using TCFC images. Initially, an examiner selected 100 cone-beam computed tomography scans, and his DICOM file was collected. Segments of the oropharynx were performed according to the manufacturer's references, with two techniques for segmentation: interactive threshold range and fixed threshold range. The results were subjected to an analysis of variance test (ANOVA) with a significance level of $5 \%$ for all statistical tests. The results found for both the analysis of the minimum sectional area and the total volume showed that the median values between the treatment groups are greater than would be expected and when there was a comparison between each group, there was a statistically significant difference $(P=$ $<0.001)$. In the results of the minimum axial area, all five programs showed statistically significant differences between them. Regarding the volume, there was a statistically significant difference in all groups, except between the software InVIVO and ITK-Snap (for this analysis).

Keywords: Image Processing Computer - Assisted; Imaging, Three-Dimensional; Airway Management; Airway Remodeling. 



\section{LISTA DE ABREVIATURA E SIGLAS}

TCFC Tomografia Computadorizada Feixe Cônico

TCMS Tomografia Computadorizada Multislice

Inf. Informação

SciELO Scientific Electronic Library Online 



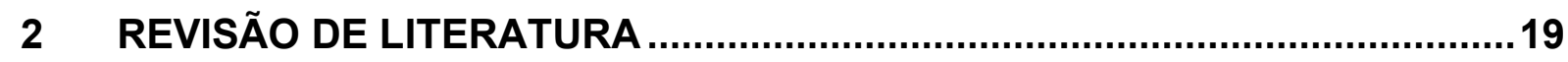

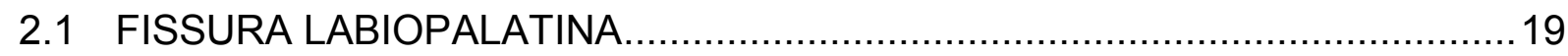

2.2 TOMOGRAFIA COMPUTADORIZADA FEIXE CÔNICO ……......................20

2.3 TCFC RESPEITA ESCALA DE HOUNSFIELD? ............................................22

2.4 USO DE SOFTWARES PARA AVALIAÇÃO DA VIA AÉREA ..........................23

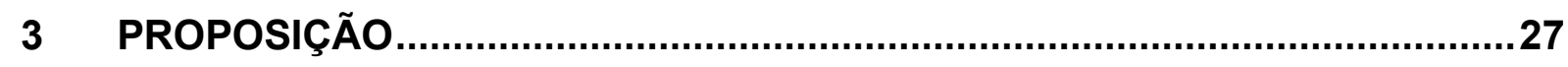

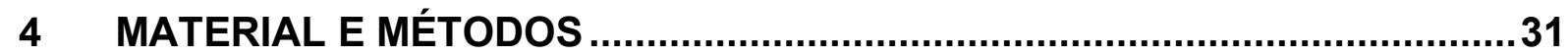

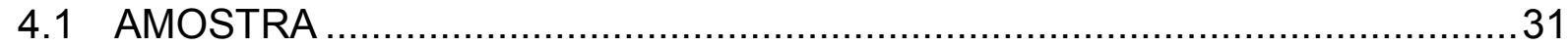

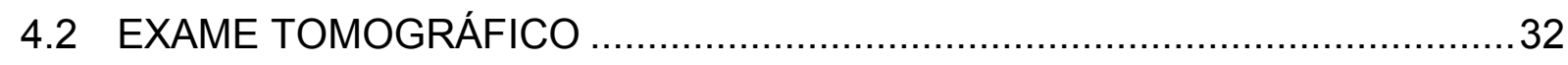

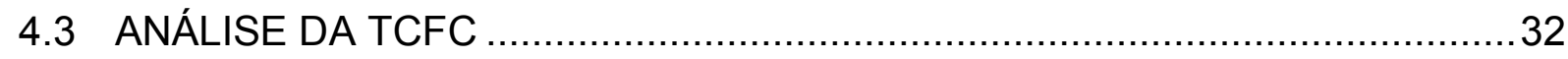

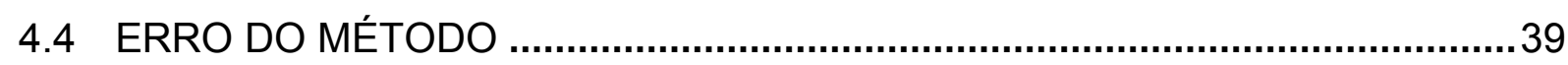

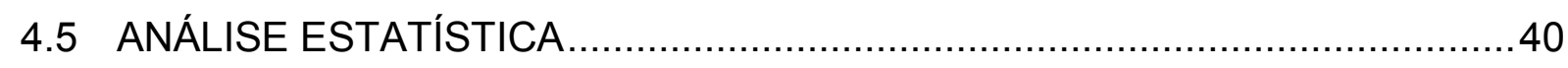

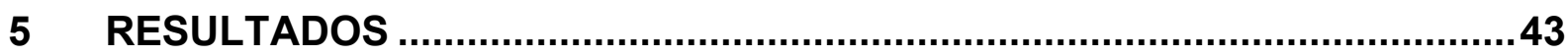

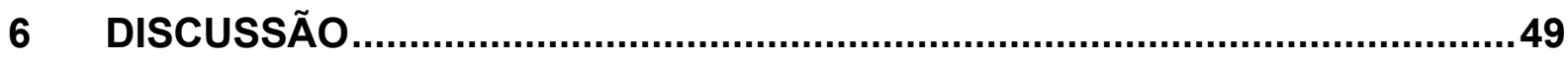

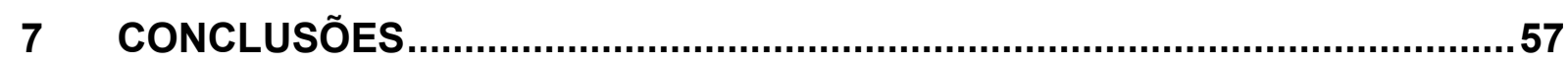

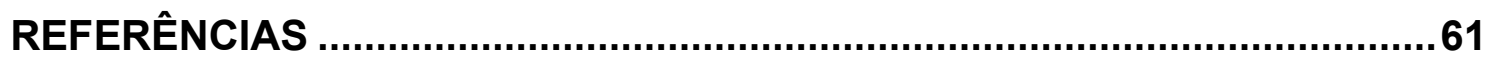

ANEXOS 



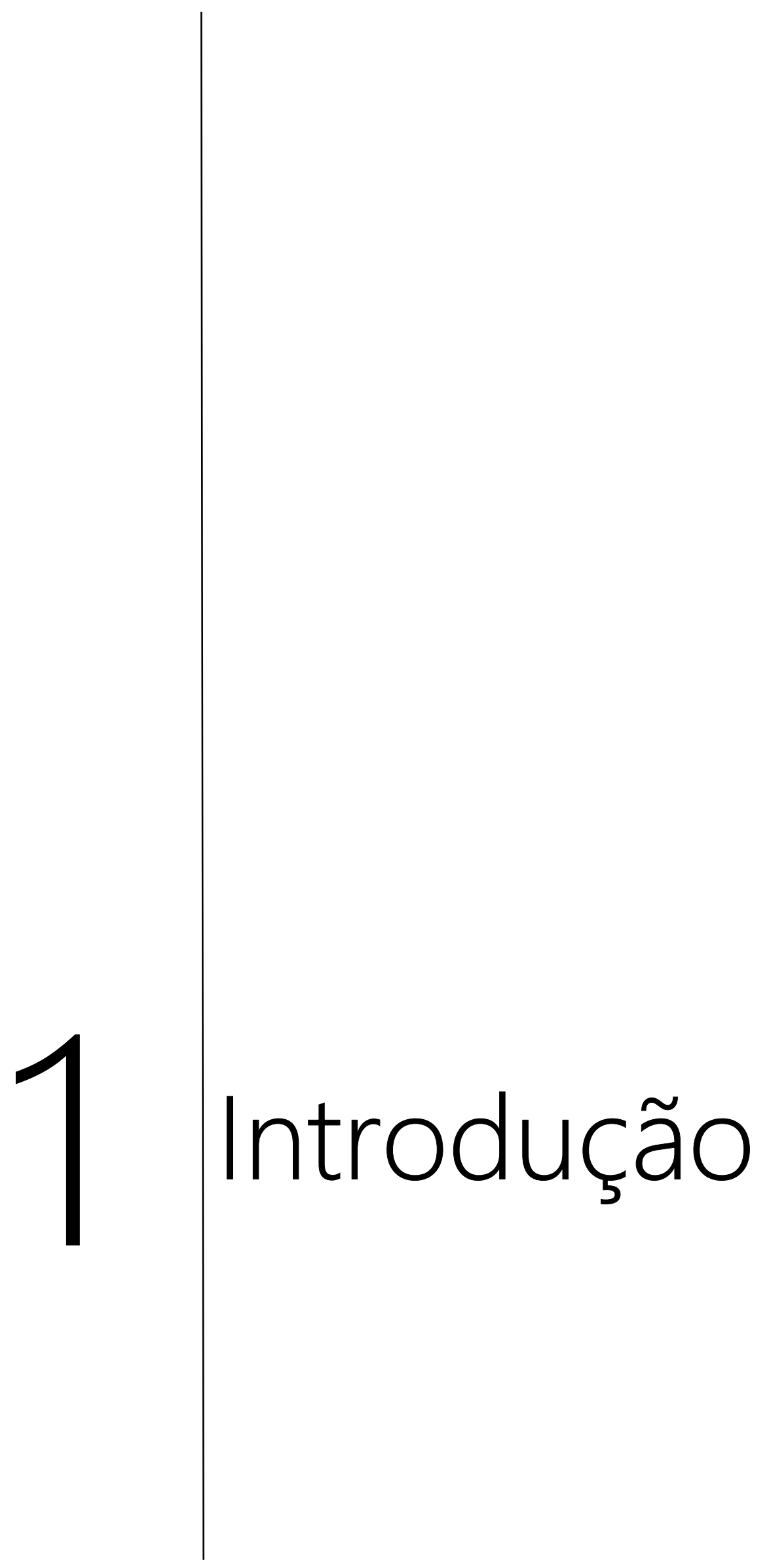





\section{INTRODUÇÃO}

Entre as anomalias craniofaciais a fissura labiopalatina (FLP) é a mais comum (SAYETTA et al., 1989), sendo uma malformação congênita que ocasiona descontinuidade na anatomia do lábio e do osso alveolar superior e palato, podendo ocorrer individualmente (apenas afetando lábio ou palato) ou simultaneamente (afetando lábio e palato, lábio e rebordo alveolar, lábio e rebordo e palato) (PINHEIRO et al., 2018).

Tais anomalias acometem precocemente os indivíduos, ainda na vida intrauterina, propriamente no período embrionário e primeiros meses do período fetal, até a $12^{\mathrm{a}}$ semana de gestação (FREITAS et al., 2012). Quanto a etiologia fatores como: agente químico, físico ou biológico, que tem ação na migração, diferenciação e proliferação de células da crista neural, com posterior envolvimento mesenquimal facial, são potenciais fatores para determinar a incidência de fissura labial e palatina. A etiopatogenia demanda da interação entre fatores genéticos e ambientais, sendo então um padrão multifatorial.

A importância na avaliação da função e da forma das vias aéreas superiores vem crescendo significativamente ao longo dos anos, pela íntima relação entre as estruturas das vias aéreas superiores, a morfologia craniofacial e a apneia e hipopneia obstrutiva do sono (GUIJARRO-MARTíNEZ E SWENNEN, 2011)

A TCFC é um exame de grande importância para análise craniofacial, bem como o cálculo do volume da via área, possibilitando também a localização da menor área axial (KIM, 2015). Com a crescente presença de alterações na morfologia das vias aéreas, em várias situações relacionadas com deformidades faciais/ esqueléticas, o diagnóstico de doenças relacionadas ao sono ganhou enorme importância na medicina moderna, levando sua incorporação ao planejamento ortodôntico/cirúrgico, permitindo melhor análise da menor área axial e sua estreita relação com síndrome da apneia obstrutiva do sono (QUAN et al., 1999; TORRES et al., 2019).

Observa-se diferentes programas para tais fins InVivo Dental, Mimics, Ondemand3D, OsiriX, Dolphin3D, NemoFAB, ITK Snap e InVesalius) (GUIJARROMARTÍNEZ E SWENNEN, 2011), mas a comparação e análise de sua precisão ainda 
é pouco relatada na literatura, quando se visa avaliar as vias aéreas superiores (El and PALOMO, 2010; WEISSHEIMER et al., 2012; PINHEIRO et al., 2018).

Dessa forma, o objetivo do presente trabalho foi comparar a medida do volume do espaço aéreo e a menor área axial da via aérea em pacientes com fissura labiopalatina por meio de cinco diferentes programas, considerando pacientes com fissura labiopalatina submetidos a cirurgia ortognática.

Espera-se, com esta pesquisa, resultados que validem, com maiores detalhes, a acurácia de softwares para análise de volume e área do espaço e vias aéreas, legitimando, assim, estudos que avaliam o aumento das vias aéreas superiores em pacientes com fissura labiopalatina, submetidos a cirurgia ortognática. 


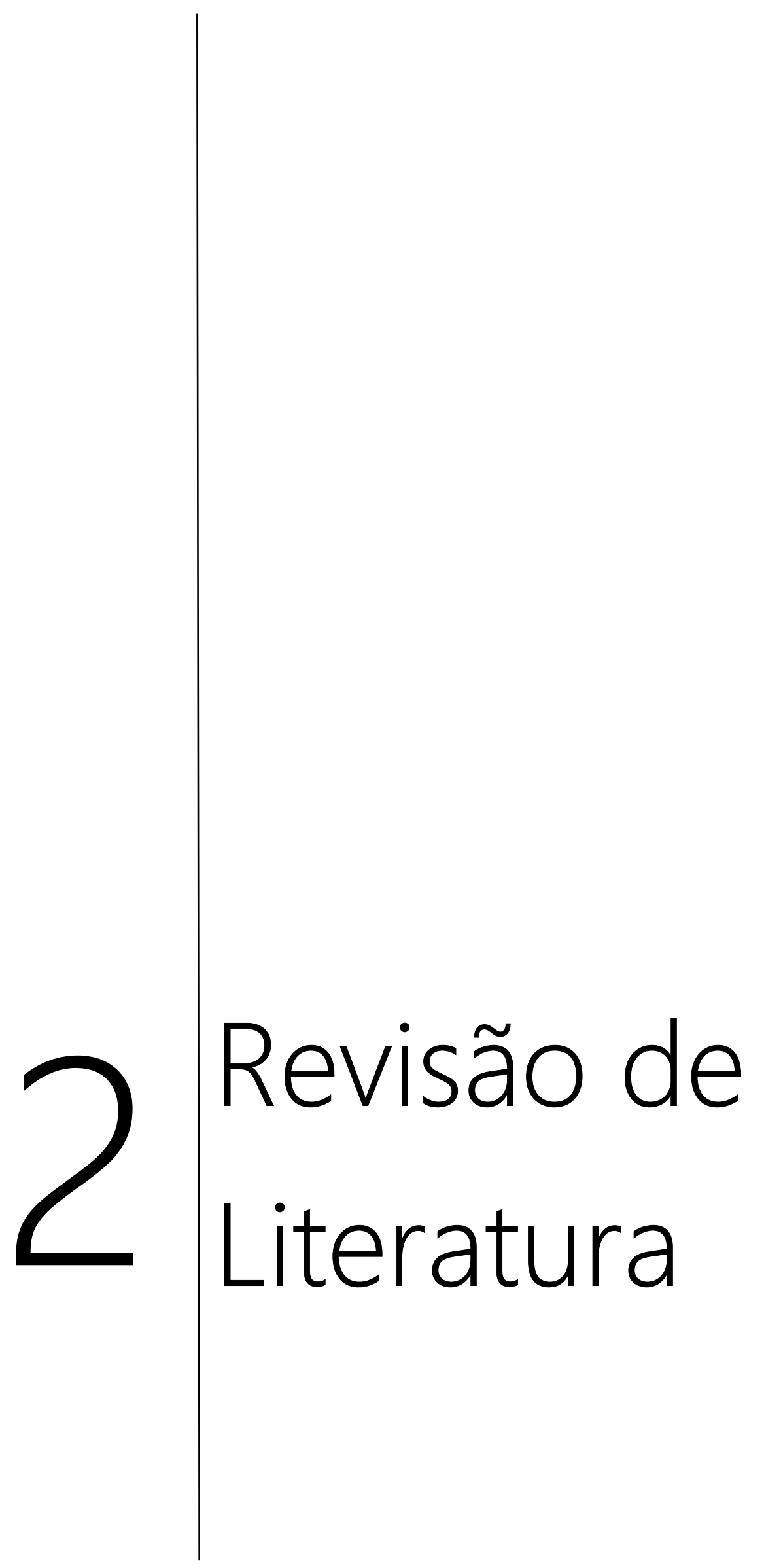





\section{REVISÃO DE LITERATURA}

\subsection{FISSURA LABIOPALATINA}

Existem diferentes classificações para as fissuras labiopalatinas (FLP), no Hospital de Reabilitação de Anomalias Craniofaciais da Universidade de São Paulo (HRAC/USP) a classificação utilizada é baseada na morfologia, preconizada por Spina et al., 1972 e modificada por Silva Filho et al., 1992. O forame incisivo é a referência anatômica, pois indica a separação entre o palato primário e secundário.

Às fissuras isoladas de palato primário, fissuras concomitantes de palato secundário e primário e isolada de palato secundário, recebem prefixos pré, trans e pós, respectivamente. Spina denomina as fissuras raras da face, aquelas que não têm associação com o forame incisivo, e Silva Filho et al., 1992 incluiu a fissura transforame mediana

Pacientes com FLP apresentam relativa incidência de deformidade dentofacial esquelética, exibindo padrão classe III (LACERDA et al., 2014; OZAWA et al., 2011) culminando com a indicação da cirurgia ortognática, com avanço maxilar e retrusão mandibular (POSNICK e RICALDE, 2004). A deformidade dentofacial é explicada pelas alterações de crescimento, devido às cirurgias prévias de lábio (queiloplastia) e palato (palatoplastia), realizadas na infância, visto que esses procedimentos alteram o crescimento tanto no sentido transversal quanto sagital dos maxilares (MCCOMB et al., 2011; TRINDADE-SUEDAM et al., 2017).

Tais deformidades resultam em alteração negativa na morfofisiologia nasal, proporcionando distorções, como hipertrofia dos cornetos, desvio de septo (TRINDADE-SUEDAM et al., 2017) e as alterações do assoalho nasal, que modificam a anatomia e fisiologia das vias aéreas superiores (YATABE-IOSHIDA et al., 2018), revelando o comprometimento das vias aéreas em $60 \%$ dos indivíduos com FLP (BERTIER; TRINDADE, 2007). Tais alterações repercutem na respiração, na fala desses pacientes, pois há redução da configuração da cavidade nasal, ocorrendo assim um aumento na resistência da passagem de ar, prejudicando o desenvolvimento craniofacial (BERTIER; TRINDADE, 2007). 


\subsection{TOMOGRAFIA COMPUTADORIZADA FEIXE CÔNICO (TCFC)}

Durante anos, a cefalometria foi o método mais utilizado em odontologia para análise do desenvolvimento craniofacial, porém se mostrou restrito quando da necessidade de avaliação das vias aéreas superiores (WEISSHEIMER et al., 2012). Informações adicionais sobre volume total e áreas seccionais foram possíveis de serem determinadas, através de imagens 3D (OGAWA et al., 2007; ABOUDARA et al., 2009; ; IWASAKI et al., 2009, KIM et al., 2010, ZHAO et al., 2010, TRINDADESUEDAM et al., 2017).

Com o advento de novas tecnologias, a TCFC se mostrou eficiente para avaliação destas vias, sendo sua acurácia e confiabilidade confirmada por diversos estudos (OGAWA et al., 2007, KIM et al., 2010; ABOUDARA et al., 2009; ). Estes avanços foram importantes também para analisar e compreender alguns problemas relacionados à respiração, relacionando-os com a anatomia craniofacial (SCHENDEL e HATCHER, 2010). Outro fato, de extrema importância demonstrado na literatura, é que a TCFC apresenta também melhores benefícios relacionados a baixa dose de radiação, boa qualidade com cortes múltiplos (WHITE et al., 2015), e observa-se também melhor precisão para delimitar tecidos moles e espaços vazios (LENZA et al., 2010).

Devido ao crescente uso deste método tomográfico, aumentou-se a busca por softwares para arquivos DICOM que permitem a avaliação e a mensuração da área craniofacial.

A literatura mostra o software Dolphin3D (11.8, Dolphin Imaging \& Management Solutions, Chatsworth, CA, USA) largamente utilizado na análise das vias aéreas superiores, através de modelos DICOM obtidos a partir da TCFC, sendo considerado padrão ouro (SCHNEIDER et al., 2015; JONES et al., 2016). Tal software apresenta imagens em alta resolução e tridimensionais, com uma interface totalmente intuitiva.

Em contrapartida, outra solução para evitar tais softwares pagos, são as opções gratuitas, de nomenclatura open source imaging (PINHEIRO et al., 2018), como ITK-SNAP, Invesalius, OsiriX, já citados na literatura (WEISSHEIMER et al., 2012; PINHEIRO et al., 2018),porém alguns deles precisam de um módulo para contemplar alguma deficiência de análise. Tais softwares gratuitos para análise da mínima área seccional utilizam do recurso do módulo SPHARM-PDM, disponível no software gratuito SlicerCMF ( $\underline{w w w . s l i c e r . o r g}$ ), como complemento na avaliação da via 
aérea, sendo tal programa operado no intuito de gerar modelos paramétricos fundamentado em esferas harmônicas.

A análise do espaço aéreo superior com a finalidade de cálculo do seu volume está intimamente ligada com a precisa segmentação, bem como uma boa qualidade da imagem. Alguns fatores são limitantes para uma boa qualidade da imagem, como: TCFC, gerenciamento da posição do paciente na tomada tomográfica, exportação do arquivo DICOM e a reconstrução do volume (LIU et al., 2010). Para uma melhor obtenção das imagens da TCFC, as configurações devem ser altas (voxel de tamanho pequeno e maior tempo de digitalização), propiciando assim uma melhor resolução (BALLRICK et al., 2008). A segmentação é a separação de uma área de interesse (via aérea) fazendo a remoção das demais estruturas construindo então um modelo virtual 3D, o que permite uma melhor avaliação e análise (GRAUER et al., 2009).

Para reconstrução 3D da via aérea, são utilizadas técnicas de segmentação, podendo ser através de métodos manuais de corte por corte, até segmentações semiautomáticas, no qual é necessário o conhecimento prévio sobre a forma e densidade radiográfica das estruturas de interesse (WEISSHEIMER et al., 2012).

$\mathrm{Na}$ manipulação manual, o programa une todos os cortes, formando uma imagem volumétrica 3D. Tal método tem a desvantagem de ser lento, o que dificulta seu uso. Em contrapartida o método semiautomático de segmentação, na maioria das vezes realizado por programas pagos, é realizado de forma mais ágil (El and Palomo, 2010). Nesse aspecto o computador realiza de forma automática a diferenciação entre as áreas de interesse, delimitando tecido mole e ar, para isto o sistema usa as diferenças nos valores de níveis de cinza (escala Hounsfield) (Weissheimer et al., 2012). Em alguns programas, a segmentação semiautomática inclui dois passos interativos: delimitação de regiões de interesse nos cortes axial, coronal e sagital e seleção da escala Hounsfield (WEISSHEIMER et al., 2012).

Por sua vez, as abordagens semiautomáticas, possuem o melhor de cada técnica, com a acurácia, eficiência e reprodutibilidade designadas aos métodos automáticos, juntamente com controle de qualidade e experiência de um pesquisador (YUSHKEVICH et al., 2005). 


\subsection{TCFC RESPEITA ESCALA DE HOUNSFIELD?}

Hounsfield (1973) criou uma maneira adequada de isolar a diminuição da radiação causada por pequenos pixels e, a partir daí, associou diferentes tons de cinza a cada valor da redução, postulando uma escala relativa, na qual o valor do ar é -1000 $\mathrm{HU}$, da água é $0 \mathrm{HU}$ e da densidade óssea é +1000 HU (onde HU é Hounsfield Unit Unidades Hounsfield). Com isto, possibilitou a medição do coeficiente de atenuação dos diferentes tecidos examinados em TC.

Os valores HU em TCFC sofrem grande variação em concordância com as mudanças na configuração de imagem, heterogeneidade do material, bem como tamanho do objeto (em direções axiais e longitudinais). Estas variações resultam em uma maior inconstância e, portanto, na não acurácia dos valores HU (RONG et al., 2010). No entanto, alguns estudos aplicam HU para medir densidade em exames de TCFC (CAMPOS et al., 2012; HAN et al., 2012; ISODA et al., 2012; WALLACE, PIKOS e PRASAD, 2014).

Yamashina et al., (2008) em seu estudo analisaram a confiabilidade da TCFC para avaliar o espaço aéreo, para tal os autores compararam medidas de densidade de tecidos moles, ar e água, concluindo assim que o resultado em valores da TCFC é limitado para cada pixel dos diferentes cortes na tomografia, porém sendo confiável na avaliação do espaço aéreo.

Em outro estudo realizado em 2011, Nackaerts et al., (2011) compararam as dimensões de densidade conseguidas em TCFC com HU em tomografia computadorizada multislice (TCMS). Concluindo que há baixa confiabilidade nos valores da densidade de imagens da TCFC, sendo influenciados pelos diferentes tomógrafos, parâmetros de imagem e posicionamento do phantom.

Valiyaparambil et al., (2012) avaliaram se os valores de cinza em regiões edêntulas eram semelhantes a qualidade óssea encontrada durante o procedimento cirúrgico, para tal os autores fizeram uma correlação entre os valores de cinza da TCFC e de HU obtidos na tomografia computadorizada. Com isto eles concluíram que os valores de tons de cinzas da TCFC auxiliam na avaliação da qualidade óssea, sendo que os mesmos podem também interferir na densidade óssea.

Silva et al., (2012) realizaram uma comparação entre valores de densidade óssea de TCFC e TCMS de possíveis regiões para instalação de implantes osseointegrados, para tal foi utilizado o valor HU de TCMS como padrão ouro para 
análise. Os resultados do trabalho mostraram que na TCFC os valores de densidade óssea em HU foram maiores quando comparados a TCMS. Os autores colocam como observação a necessidade de melhorias técnicas na TCFC, bem como melhoria de novos softwares que pudessem contribuir com a redução de valores em HU observados nos dois sistemas tomográficos.

\subsection{USO DE SOFTWARES PARA AVALIAÇÃO DA VIA AÉREA}

Palomo et al., (2010) comparam em seu estudo confiabilidade e precisão de três softwares (DICOM) disponíveis comercialmente para medir os volumes das vias aéreas superiores, entre eles: Dolphin3D (version 11, Dolphin Imaging \& Management Solutions, Chatsworth, Calif), InVivoDental (version 4.0.70, Anatomage, San Jose, Calif), and OnDemand3D (version 1.0.1.8407, CyberMed, Seoul, Korea), com isto os autores selecionaram de forma aleatória trinta TCFC, para cálculo dos volumes das vias aéreas. Os autores concluíram que os três softwares são confiáveis em seus cálculos de volume de vias aéreas e mostraram alta correlação de resultados, mas pouca precisão, sugerindo erros sistemáticos.

Em 2012, Weissheimer et al., (2012) fizeram um estudo comparando a acurácia de seis softwares para avaliação tridimensional das vias aéreas superiores. Neste estudo os autores demonstraram a importância da acurácia da segmentação volumétrica das vias aéreas superiores. Nos resultados encontraram semelhanças em quatro softwares, dentre eles o Dolphin3D e ITK-SNAP, com valores significantemente mais precisos que os demais na avaliação das vias aéreas superiores.

Pinheiro et al., (2018) avaliaram a precisão da reconstrução volumétrica da faringe, comparando o volume e a área transversal mínima (mCSA) determinada com aplicações de código aberto (ITK-Snap, www.itksnap.org; SlicerCMF) e software comercial pago (Dolphin3D). Foi analisada uma amostra de 35 TCFC de pacientes com fissura labiopalatina unilateral, com média de idade de $29 \pm 15$ anos. Modelos volumétricos tridimensionais da faringe foram reconstruídos usando segmentação semi-automática e as aplicações ITK-Snap (G1) e Dolphin3D (G2). Assim os volumes e áreas transversais mínimas foram determinadas, sendo o erro inter e intraobservador calculados usando o teste ICC. Os autores concluíram que as medidas de volume e área seccional mínima são estatisticamente semelhantes entre as 
aplicações. Portanto, aplicações de código aberto podem ser uma opção viável para avaliar as dimensões das vias aéreas superiores usando exames TCFC.

Kamaruddin et al., (2019) avaliaram uma amostra de 11 TCFC, utilizando os softwares Invivo5 (Anatomage) e Romexis (versão 3.8.2.R, Planmeca). Os autores concluíram que a média do volume e área seccional mínima não foi significativamente diferente entre os softwares avaliados.

Torres et al., (2019) realizaram um estudo com o objetivo de avaliar a confiabilidade de dois diferentes softwares (Dolphin3D e InVivoDental) para análise tridimensional da via aérea. Os autores encontraram diferenças significativas no volume da orofaringe $(P=0,002)$ e localização da área mínima da nasofaringe $(P=$ $0,009)$. Sendo o software Dolphin 3D o que apresentou valores de volume superiores. Os sistemas de softwares comparados Dolphin3D e InVivoDental foram considerados confiáveis, porém não iguais, mostrando que o InVivoDental subestima os valores das vias aéreas, enquanto o Dolphin3D superestima. 


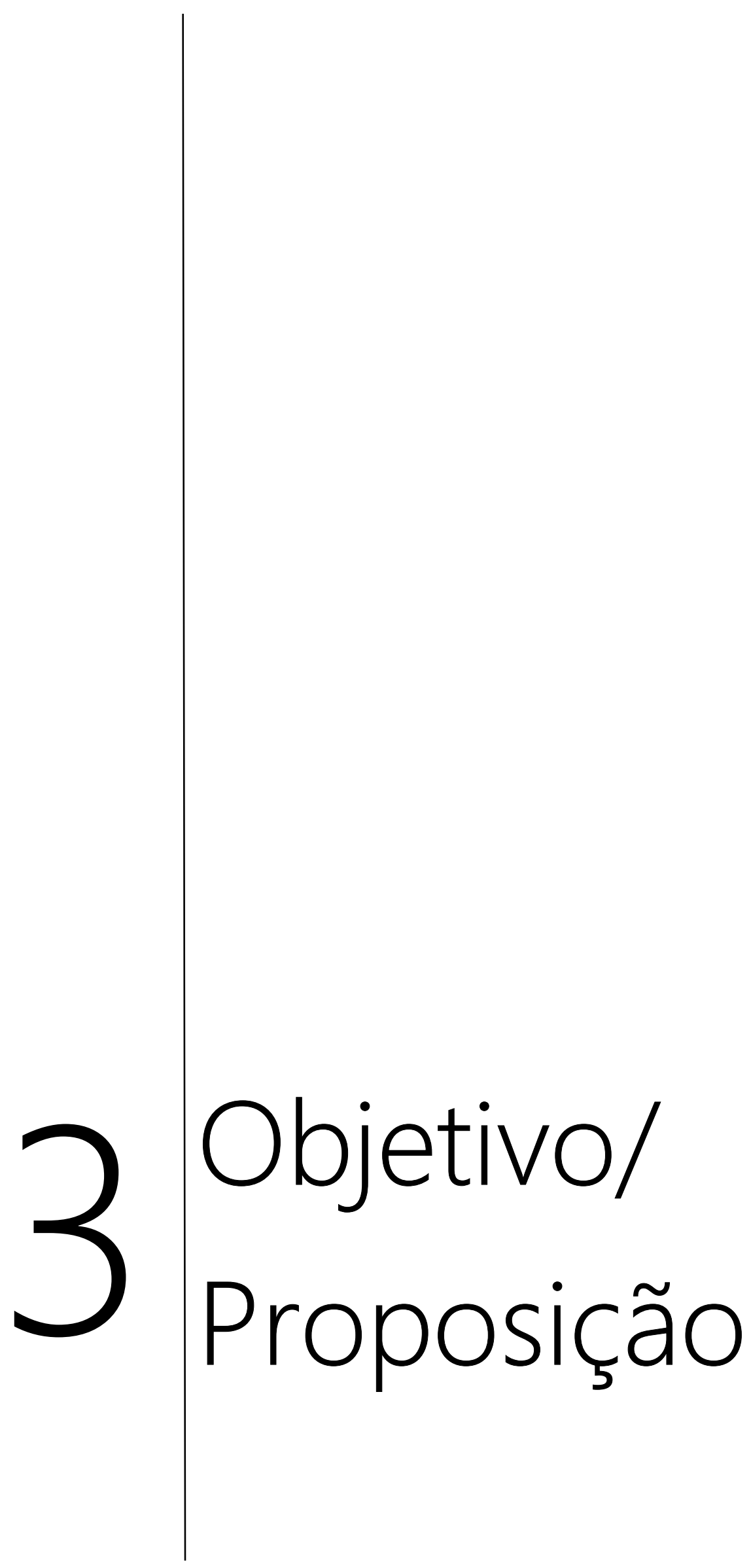





\section{PROPOSIÇÃO}

O objetivo do presente estudo foi avaliar as diferenças na aferição do volume do espaço aéreo e a área seccional mínima realizada por 5 programas de segmentação. A hipótese nula testada é que não há diferenças significativas nas medidas do volume e da área seccional mínima, quando comparados os cinco programas utilizados na análise. 



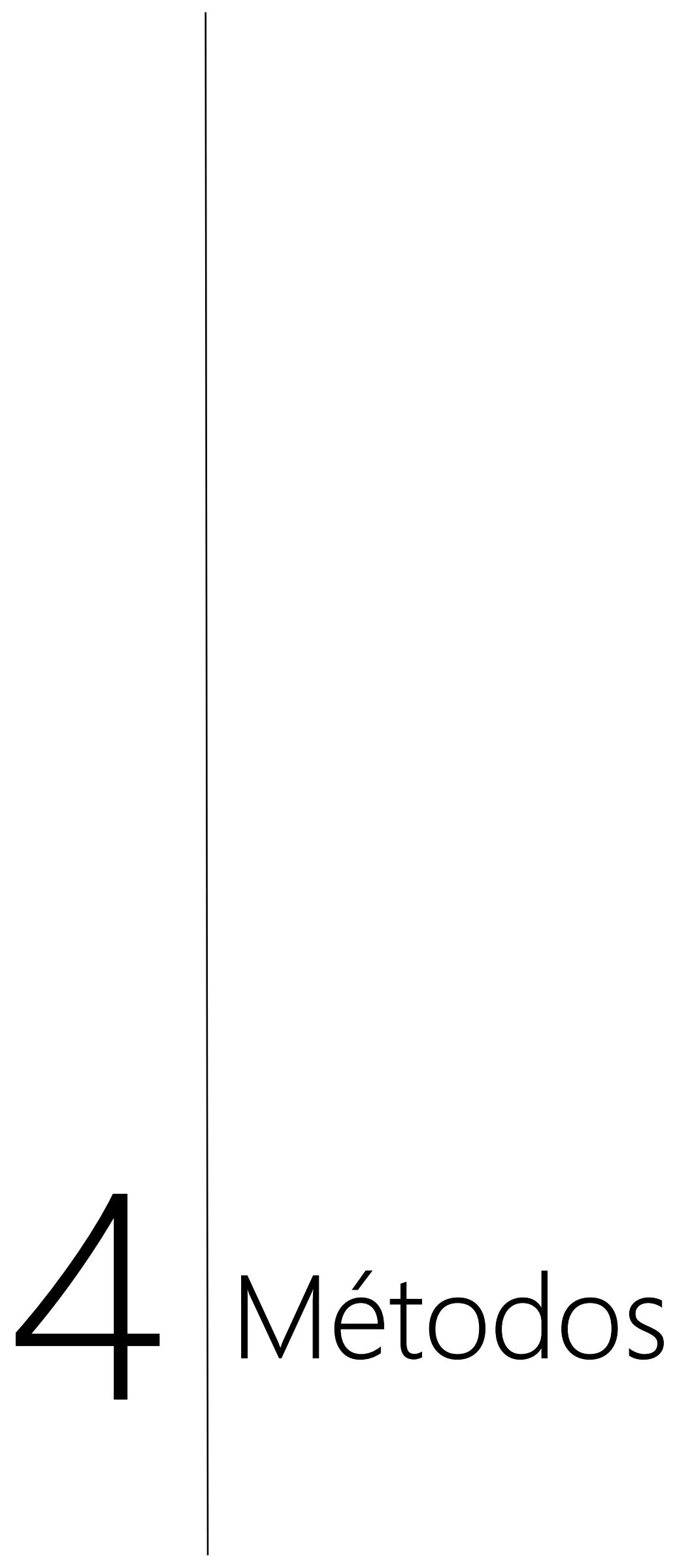





\section{MÉTODOS}

A presente pesquisa, de caráter retrospectivo, foi aprovada pelo Comitê de Ética e Pesquisa do Hospital de Reabilitação de Anomalias Craniofaciais (HRAC/USP), sob parecer n 3.605.233 (CAAE:20593219.4.0000.5441). Os exames tomográficos foram obtidos através do banco de dados do referido hospital, e solicitados previamente com o objetivo de planejamento/diagnóstico para cirurgia ortognática.

\subsection{AMOSTRA}

Para a definição do tamanho da amostra foi considerado erro alfa de $5 \%$, beta de $80 \%$ e desvio padrão de $1,220 \mathrm{~mm}^{3}$ de acordo com Pinheiro et al., (2018) e uma diferença significativa de 0,7 chegando assim em um $n=73$ TCFC para ser avaliada nos 5 diferentes softwares, quando se calcula a menor área axial e o volume da via aérea.

Desta forma foram selecionadas 100 TCFC de pacientes com fissura labiopalatina transforame incisivo unilateral do arquivo de imagens do Hospital de Reabilitação de Anomalias Craniofaciais da Universidade de São Paulo. A seleção das tomografias foi realizada por amostragem intencional utilizando o site randomization (randomizer.org) e selecionando a partir de 450 tomografias, 100 de forma aleatória.

Os critérios de inclusão foram:

- Paciente com fissura labiopalatina transforame unilateral completa

- Faixa etária entre 18 a 40 anos

- Ausência de síndrome

- Tomografia computadorizada de feixe cônico com boa qualidade sem muitos artefatos. 


\subsection{EXAME TOMOGRÁFICO}

Todas as TCFCs foram realizadas no mesmo aparelho e com a mesma técnica no tomógrafo iCAT (Imaging Sciences International, Hatfield, PA, EUA), sob as seguintes normas técnicas: parâmetros: 120 kVp, 5 mA, campo de visão (FOV) $16 \mathrm{~cm}$ $21 \mathrm{~cm}$ e $0,3 \mathrm{~mm} 3$ voxel, exportados em arquivos DICOM.

\subsection{ANÁLISE DA TCFC}

Um examinador treinado e calibrado com experiência na análise de imagens tomográficas e na manipulação de software de imagem analisou independentemente e individualmente todas as imagens em uma sala silenciosa e escura.

Com o intuito de determinar o volume da via aérea, foram criados modelos volumétricos tridimensionais, os quais foram reconstruídos e mensurados pelos 5 softwares de imagem (PINHEIRO et al., 2018). Com isto as referências anatômicas para segmentação da orofaringe foram: borda ântero-inferior da quarta vértebra cervical (C4), borda inferior-posterior do osso hióide, parede faríngea anterior e basal, e limite superior anterior do osso palatino do palato anterior, formando assim um retângulo (Figura 1) (PINHEIRO et al., 2018).

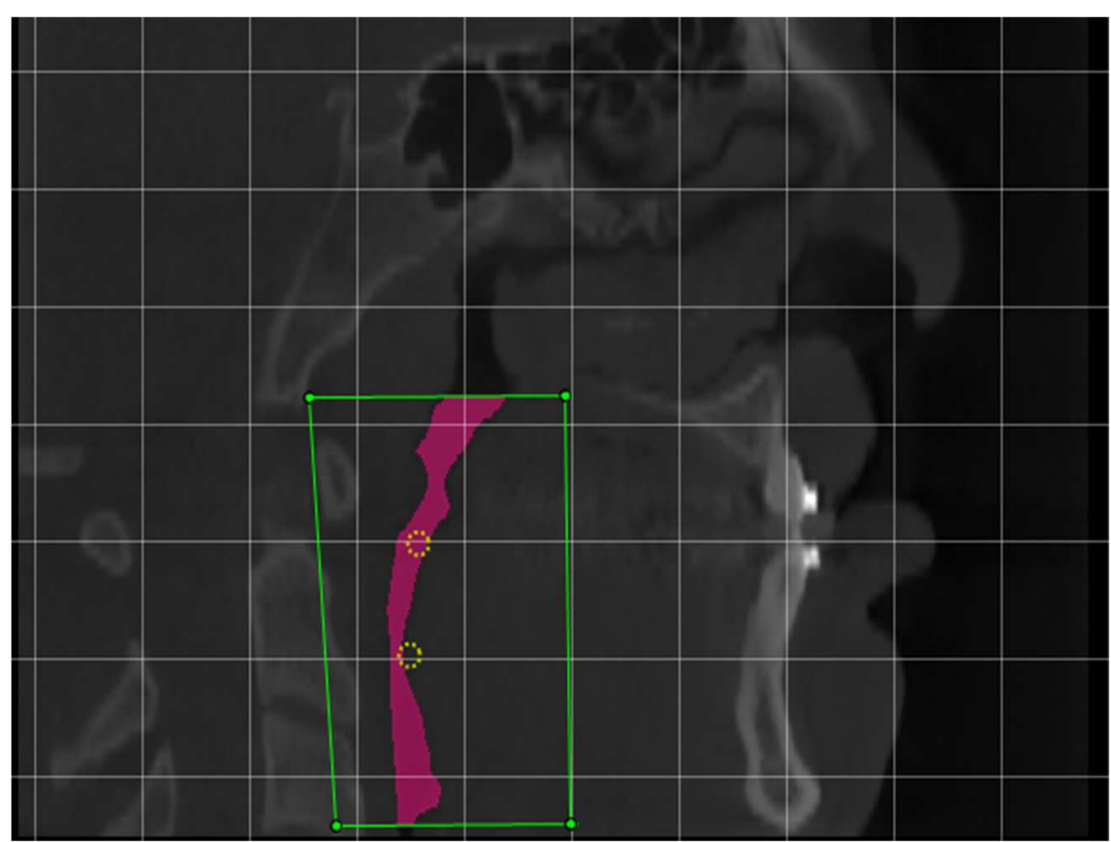

Fonte:Autor

Figura 1: Imagem de TCFC na vista sagital, com a região de interesse da via aérea delimitada (retângulo verde) 
Para o presente estudo foram selecionados 5 programas para visualização e/ou segmentação de imagens de tomografia computadorizada utilizados para 0 diagnóstico e planejamento de cirurgias e traumatologia bucomaxilofacial. Os programas selecionados foram Dolphin3D, ITK-Snap, InVivoDental, InVesalius e NemoFAB. As especificações de cada software são mostradas na Tabela I.

Tabela I. Software de imagem para TCFC comparado neste estudo

\begin{tabular}{r|ll} 
Software & Descrição & Sistema operacional \\
\hline Dolphin3D & $\begin{array}{l}\text { Version 11.7; Dolphin Imaging \& } \\
\text { Management } \\
\text { Solutions, Chatsworth, Calif }\end{array}$ & Windows \\
$\begin{array}{r}\text { InVivoDental } \\
\text { InVesalius } \\
\text { ITK-Snap }\end{array}$ & $\begin{array}{l}\text { Version 5.0; Anatomage, San Jose, } \\
\text { Calif }\end{array}$ & Windows \\
NemoFAB & $\begin{array}{l}\text { Version 2.2.0; www.itksnap.org } \\
\text { Madrid (España) }\end{array}$ & $\begin{array}{l}\text { Windows } \\
\text { Winux }\end{array}$ \\
& & $\begin{array}{l}\text { Windows } \\
\text { Wac OS X X }\end{array}$ \\
\end{tabular}

As segmentações da via aérea foram realizadas de acordo com as referências do fabricante, com duas técnicas para segmentação: intervalo limiar interativo e intervalo limiar fixo. No limiar interativo, o examinador verificou o melhor intervalo com base em uma análise visual dos limites anatômicos da via aérea nos cortes axial, sagital e coronal. Já no intervalo de limiar fixo, estabeleceu-se entre -1000 a -587 níveis de cinza, para testar a variabilidade entre os programas. As segmentações com teste interativo foram realizadas com o Dolphin3D, e com o teste fixo o ITK-Snap, InVivoDental, InVesalius e NemoFAB (WEISSHEIMER et al., 2012).

Às segmentações nos 5 programas tiveram suas particularidades, com diferentes ferramentas e recursos para segmentar as vias aéreas superiores. As principais comparações de cada programa de software de imagem são descritas na Tabela II. 
Tabela II. Principais comparações entre os 5 softwares de imagem utilizados neste estudo

\begin{tabular}{|c|c|c|c|c|c|}
\hline Software & Dolphin3D & InVivoDental & InVesalius & ITK-Snap & NemoFAB \\
\hline Files & DICOM & DICOM & DICOM & MULTIPLE & DICOM \\
\hline $\begin{array}{l}\text { TIPO DE } \\
\text { SEGMENTAÇÃO }\end{array}$ & $\begin{array}{l}\text { Segmentação rápida } \\
\text { das vias aéreas } \\
\text { superiores } \\
\text { Boa sensibilidade de } \\
\text { segmentação } \\
\text { A segmentação } \\
\text { pode ser verificada } \\
\text { em 2D } \\
\text { fatias (axial, coronal } \\
\text { e sagital) }\end{array}$ & $\begin{array}{l}\text { Unidades de } \\
\text { intervalo de } \\
\text { limite (níveis de } \\
\text { cinza) } \\
\text { compatíveis } \\
\text { com outro } \\
\text { software de } \\
\text { imagem } \\
\text { Segmentação } \\
\text { rápida das vias } \\
\text { aéreas } \\
\text { superiores }\end{array}$ & $\begin{array}{l}\text { A } \\
\text { segmentação } \\
\text { pode ser } \\
\text { verificada em } \\
\text { fatias 2D }\end{array}$ & $\begin{array}{l}\text { A segmentação } \\
\text { pode ser } \\
\text { verificada em } \\
\text { fatias 2D } \\
\text { Ferramentas } \\
\text { para corrigir a } \\
\text { segmentação em } \\
\text { fatias 2D } \\
\text { Unidades de } \\
\text { intervalo de } \\
\text { limite (níveis de } \\
\text { cinza) } \\
\text { compatíveis } \\
\text { com outro } \\
\text { software de } \\
\text { imagem }\end{array}$ & $\begin{array}{l}\text { Unidades de } \\
\text { intervalo de } \\
\text { limite (níveis de } \\
\text { cinza) } \\
\text { compatíveis } \\
\text { com outro } \\
\text { software de } \\
\text { imagem } \\
\text { Segmentação } \\
\text { rápida das vias } \\
\text { aéreas } \\
\text { superiores }\end{array}$ \\
\hline MENSURAÇÃO & $\begin{array}{l}\text { Cálculo de via aérea } \\
\text { e área seccional } \\
\text { mínima de forma } \\
\text { automática. }\end{array}$ & $\begin{array}{l}\text { Cálculo de via } \\
\text { aérea e área } \\
\text { seccional mínima } \\
\text { de forma } \\
\text { automática. }\end{array}$ & $\begin{array}{l}\text { Cálculo de via } \\
\text { aérea de } \\
\text { forma } \\
\text { automática, } \\
\text { sendo } \\
\text { necessário } \\
\text { exportação } \\
\text { exportar para } \\
\text { o software } \\
\text { SlicerCMF para } \\
\text { criar modelo } \\
\text { 3D e calcular } \\
\text { área seccional } \\
\text { mínima } \\
\text { com auxílio do } \\
\text { módulo } \\
\text { SPHARM-PDM }\end{array}$ & $\begin{array}{l}\text { Cálculo de via } \\
\text { aérea de forma } \\
\text { automática, } \\
\text { sendo necessário } \\
\text { exportação } \\
\text { exportar para o } \\
\text { software } \\
\text { SlicerCMF para } \\
\text { criar modelo 3D } \\
\text { e calcular área } \\
\text { seccional mínima } \\
\text { com auxílio do } \\
\text { módulo } \\
\text { SPHARM-PDM }\end{array}$ & $\begin{array}{l}\text { Cálculo de via } \\
\text { aérea e área } \\
\text { seccional } \\
\text { mínima de } \\
\text { forma } \\
\text { automática. }\end{array}$ \\
\hline $\begin{array}{l}\text { VISUALIZAÇÃO } \\
\text { 3D }\end{array}$ & $\begin{array}{l}\text { Mostra uma } \\
\text { renderização 3D } \\
\text { automática da TCFC. }\end{array}$ & $\begin{array}{l}\text { Mostra uma } \\
\text { renderização 3D } \\
\text { automática da } \\
\text { TCFC. }\end{array}$ & $\begin{array}{l}\text { Mostra uma } \\
\text { renderização } \\
\text { 3D automática } \\
\text { da TCFC. }\end{array}$ & $\begin{array}{l}\text { Mostra modelos } \\
\text { volumétricos } \\
\text { apenas das } \\
\text { estruturas } \\
\text { segmentadas }\end{array}$ & $\begin{array}{l}\text { Mostra uma } \\
\text { renderização 3D } \\
\text { automática da } \\
\text { TCFC. }\end{array}$ \\
\hline $\begin{array}{l}\text { MÉTODO DE } \\
\text { SALVAMENTO }\end{array}$ & $\begin{array}{l}\text { Salva os modelos } \\
\text { volumétricos no } \\
\text { software. Não é } \\
\text { possível exportar } \\
\text { dados. }\end{array}$ & $\begin{array}{l}\text { Salva os modelos } \\
\text { volumétricos no } \\
\text { software. Não é } \\
\text { possível exportar } \\
\text { dados. }\end{array}$ & $\begin{array}{l}\text { Modelos } \\
\text { volumétricos } \\
\text { podem ser } \\
\text { salvos como } \\
\text { arquivos } \\
\text { independentes } \\
\text { e exportados } \\
\text { para } \\
\text { diferentes } \\
\text { softwares }\end{array}$ & $\begin{array}{l}\text { Modelos } \\
\text { volumétricos } \\
\text { podem ser salvos } \\
\text { como arquivos } \\
\text { independentes e } \\
\text { exportados para } \\
\text { diferentes } \\
\text { softwares }\end{array}$ & $\begin{array}{l}\text { Salva os } \\
\text { modelos } \\
\text { volumétricos no } \\
\text { software. Não é } \\
\text { possível } \\
\text { exportar dados. }\end{array}$ \\
\hline
\end{tabular}

No programa Dolphin3D, após importar arquivo DICOM do paciente, o examinador selecionou os pontos no corte sagital da via área delimitando assim o espaço aéreo (Imagem 24). 


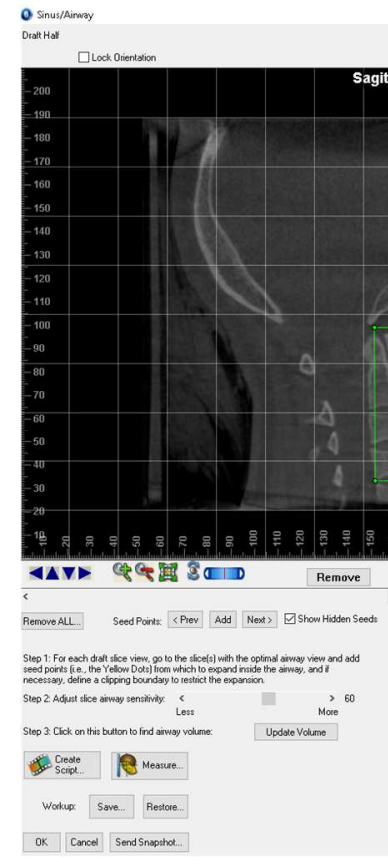

Fonte:Autor
Figura 2: Imagem de TCFC no software Dolphin3D, com a região de interesse da via aérea delimitada (retângulo verde)

No programa InVivoDental se fez necessário observar o limite mais superior e inferior, pois há uma restrição quando comparado ao programa Dolphin3D em delinear retângulo formado pelas referências anatômicas (Figura 3). 


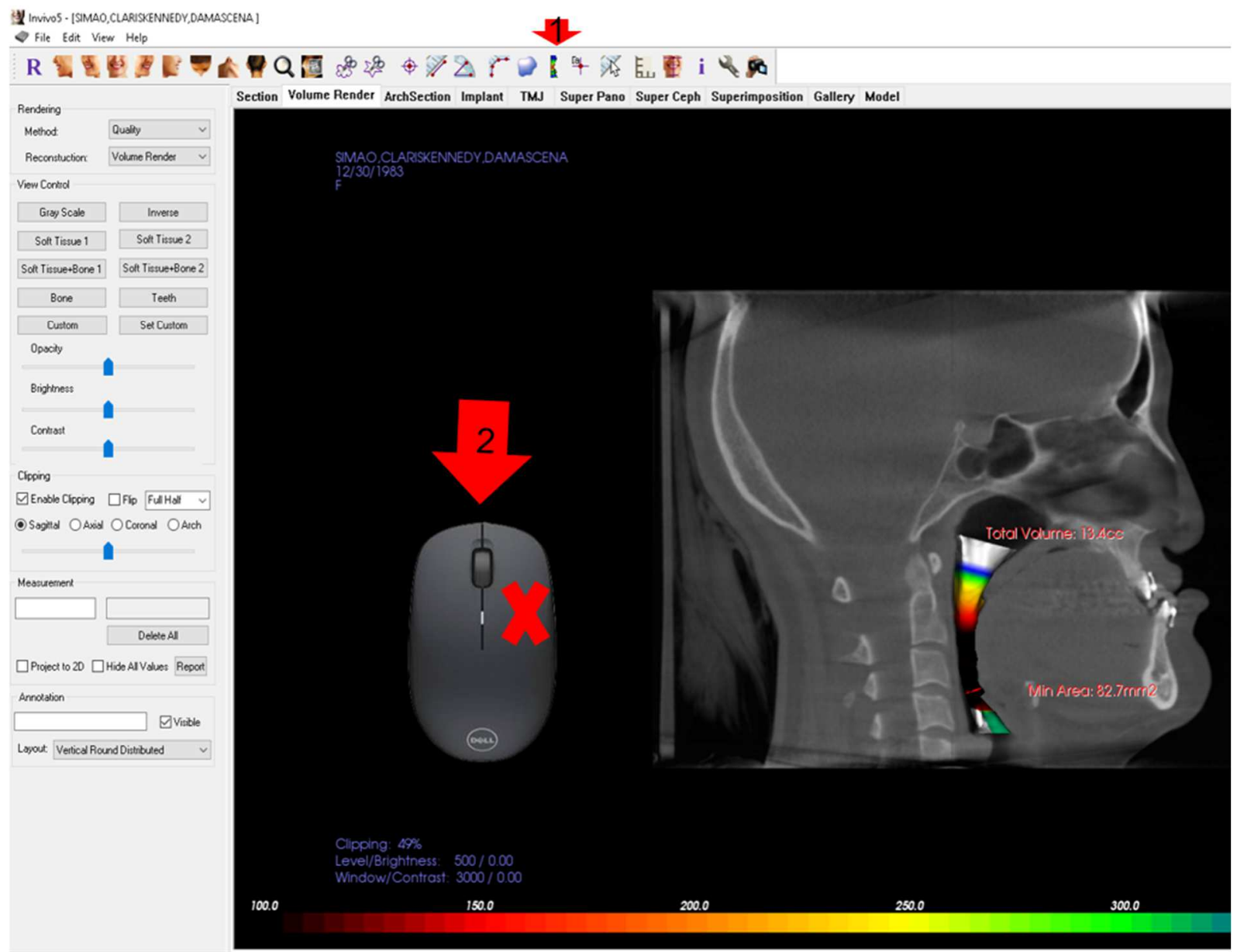

FPS Quality 20.1

Fonte:Autor

Figura 3: Imagem de TCFC no software InVivoDental, com a região de interesse da orofaringe preenchida de forma automática.

No programa InVesalius a segmentação da via aérea deve ser realizada utilizando referências do limite superior e inferior, sendo que o preenchimento do espaço aéreo precisa ser conferido em cada corte nos três planos (axial, sagital, coronal). Após pintar todas as fatias dentro dos limites previamente definidos, voltou se a imagem com o intuito de encontrar quaisquer inconsistências nos planos coronal e sagital, em seguida, as imagens já pintadas foram renderizadas, obtendo assim um volume tridimensional. 

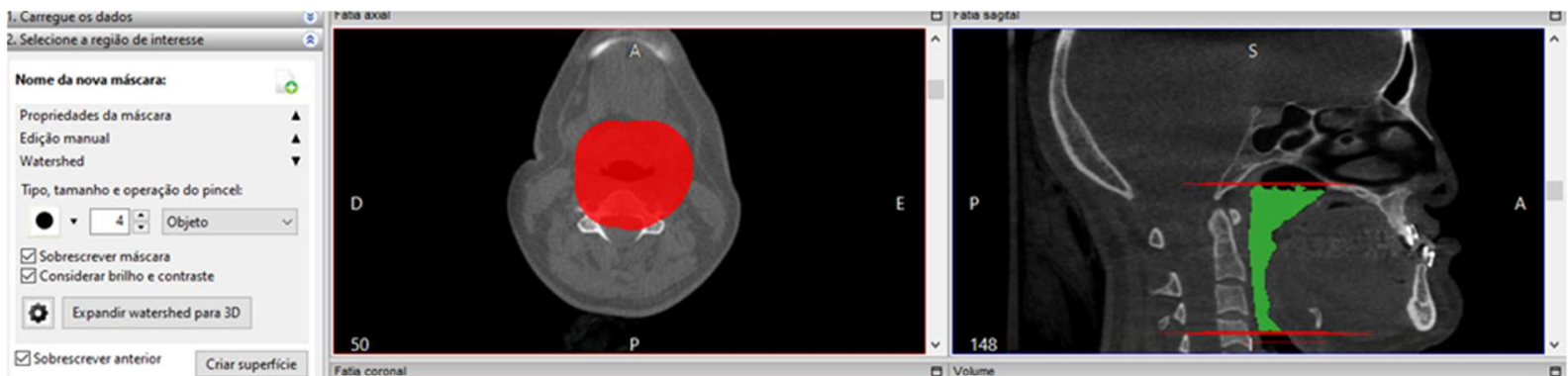

3. Configure a supeticie 30 4. Exporte os dedos

Mascaras Superficies 30 Mediços

Nome Volume (m... Área $\left(\mathrm{mm}^{3}\right)$

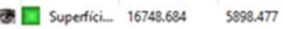

$B \times \otimes$
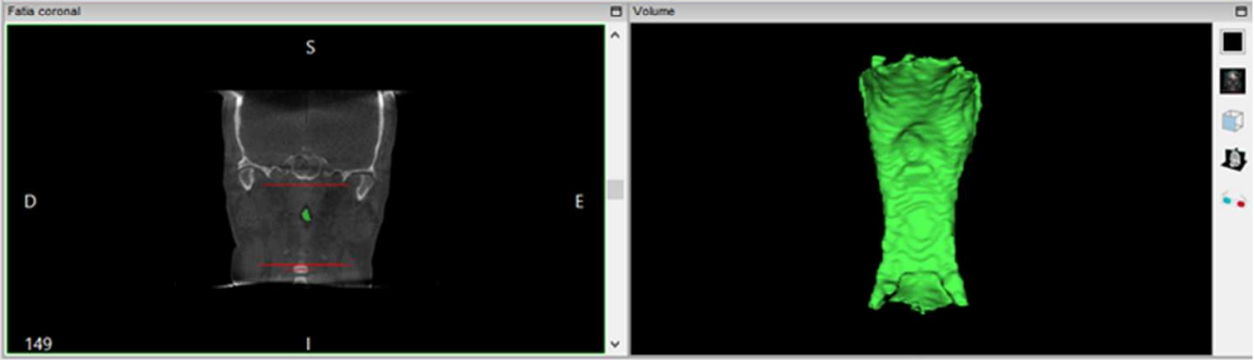

Fonte:Autor

Figura 4: Imagem de TCFC no software InVesalius , com a região de interesse da via aérea sendo delimitada.

O programa ITK-Snap necessitou de uma segmentação com limiar de limite fixo, com isto após importação dos arquivos DICOM a segmentação foi realizada seguindo padrão (- 1000 a -587 níveis de cinza), mesmo assim é possível a conferência em cada corte nos três planos (axial, sagital, coronal) (Figura 5).

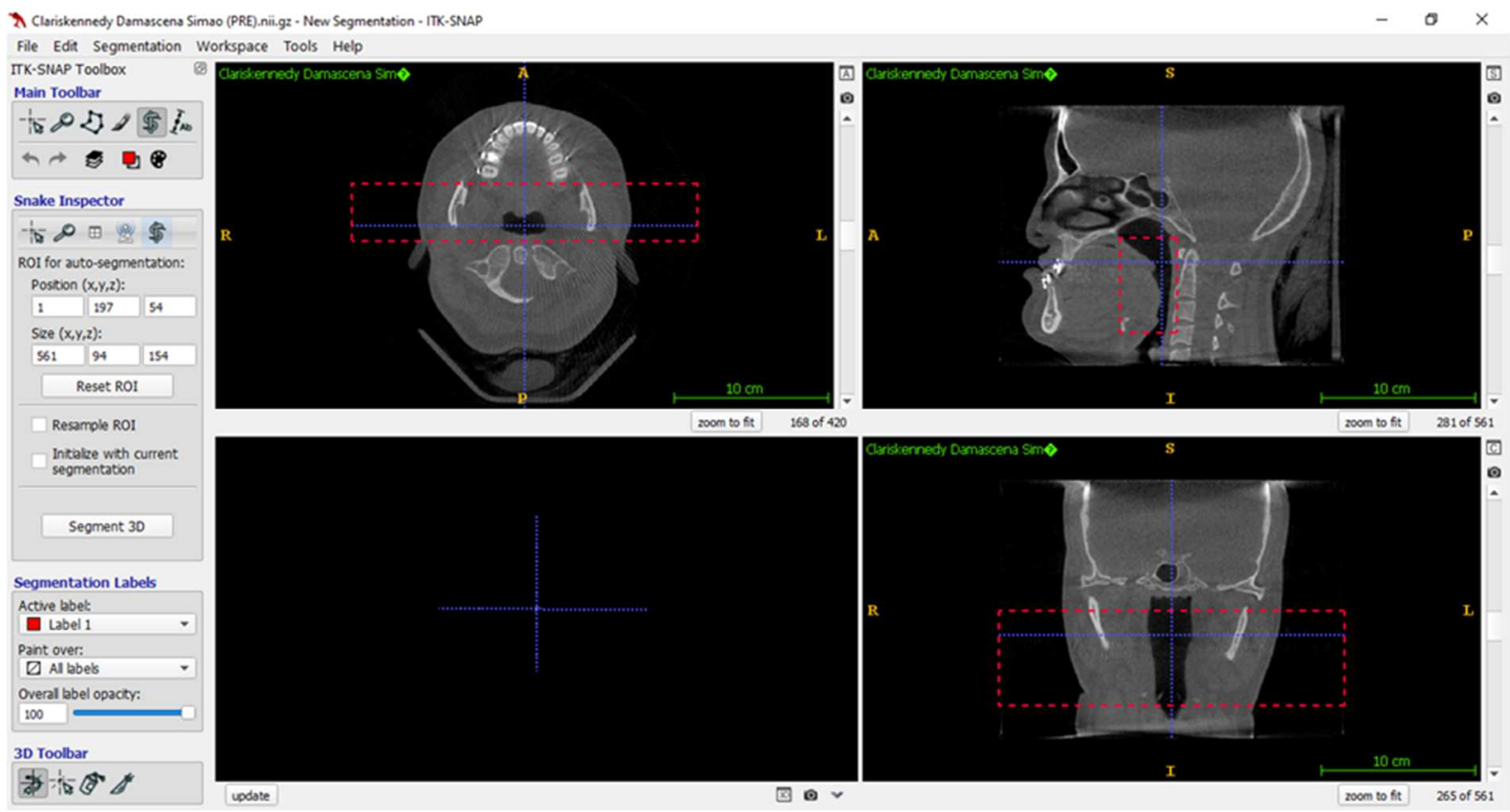

Fonte:Autor

Figura 5: Imagem de TCFC no software ITK-Snap, com a região de interesse da via aérea sendo delimitada. 
O programa NemoFAB faz segmentação com limiar de limite fixo, sendo então usado padrão (- 1000 a - 587 níveis de cinza), após importação dos arquivos DICOM foi delimitada a via aérea seguindo as referências anatômicas, logo em seguida o programa gera de forma automática, o volume do espaço selecionado.

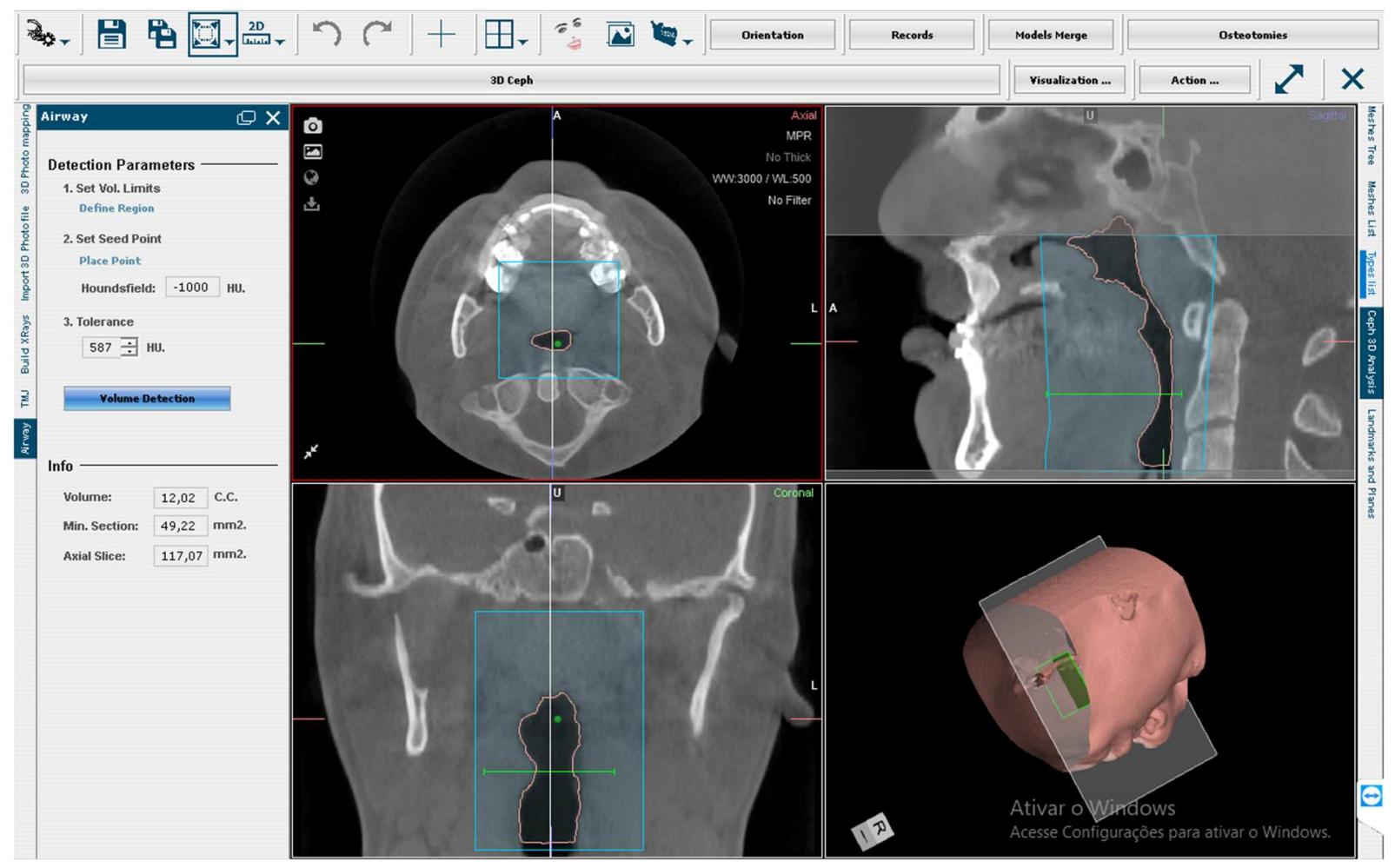

Fonte:Autor

Figura 6: Imagem de TCFC no software InvivoDental , com a região de interesse da via aérea sendo delimitada

A aquisição do volume do espaço aéreo foi automática nos programas Dolphin, InvivoDental e NemoFAB em todos os programas avaliados. A área seccional mínima é calculada automaticamente pelos programas Dolphin3D, InVivoDental e NemoFAB. No programa ITK-Snap e InVesalius foi necessário realizar o fatiamento do modelo 3D para obtenção da área seccional mínima. Para realizar o fatiamento foi utilizado o Slicer CFM com o módulo SPHARMPDM. (Figura 2) (PINHEIRO et al., 2018). 


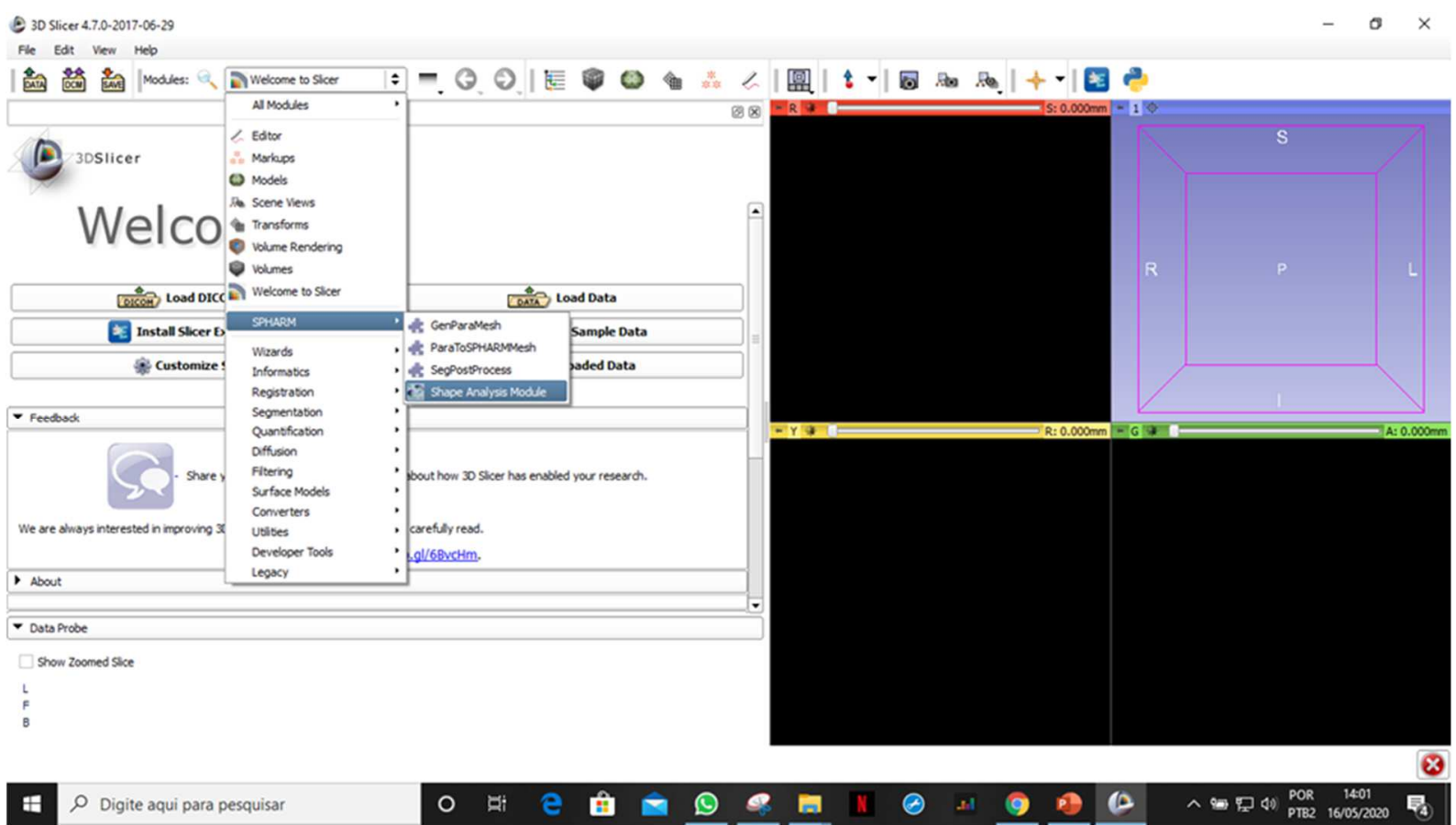

Figura 7: Imagem do software SLICER para uso dom módulo SPHARMPDM.

\subsection{ERRO DO MÉTODO}

Foi realizada a calibração intra-examinador selecionando aleatoriamente 30 exames de TCFC e todas as medidas foram realizadas nos 5 programas. As medidas foram repetidas com intervalo de 15 dias e o teste aplicado foi o intervalo de correlação intraclasse (ICC/Quadro 3), e a classificação utilizada foi pobre (ICC, 0,40); justo a bom (0,40 \#ICC \# 0.75); e excelente (ICC, 0,75) (WALTER et al., 1998).

Somente quando a concordância intra-examinador foi maior que 0,8 , todas as imagens foram analisadas, como demonstrado na tabela (1). Todas as análises foram realizadas utilizando os sistemas InVivoDental (versão 5.4, Anatomage, CA, EUA), Dolphin 3D (versão 11.7; Dolphin Imaging Systems, CA, EUA), ITK-Snap (versão 3.8.0, (YUSHKEVICH et al., , 2006), InVesalius (versão 3.1.1, Renato Archer (CTI), Brasil) e NemoFAB 3D-OS (Digital Orthognathic Surger From Planning to The Surgical Stent, Software Nemotec , S.L., Madrid, Spain) em uma sala silenciosa e escura. 


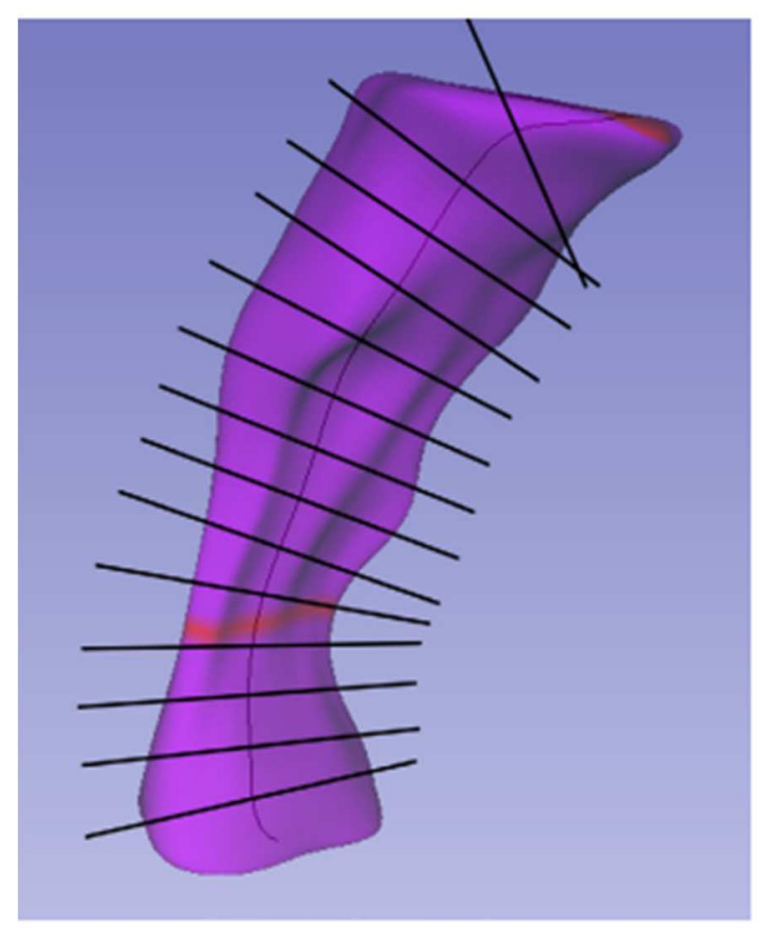

Fonte: Pinheiro et al., , 2018

Figura 2: Eixo médio e mCSA realçado obtido com o módulo SPHARM-PDM

\subsection{ANÁLISE ESTATÍSTICA}

Os dados foram tabulados em uma planilha do Excel (Microsoft, Redmond, Wash) e o teste de normalidade para as duas variáveis (volume e área seccional mínima) nos 5 grupos (Dolphin, Invivo, ITK-Snap, Invesalius e NemoFAB) foi Shapiro-Wilk, a amostra não passou pelo teste de normalidade e a comparação foi realizada pelo teste de Friedman. Para a comparação múltipla utilizou-se o teste de Tukey. Para a comparação entre grupos considerou-se um nível de significância de $5 \%$. 


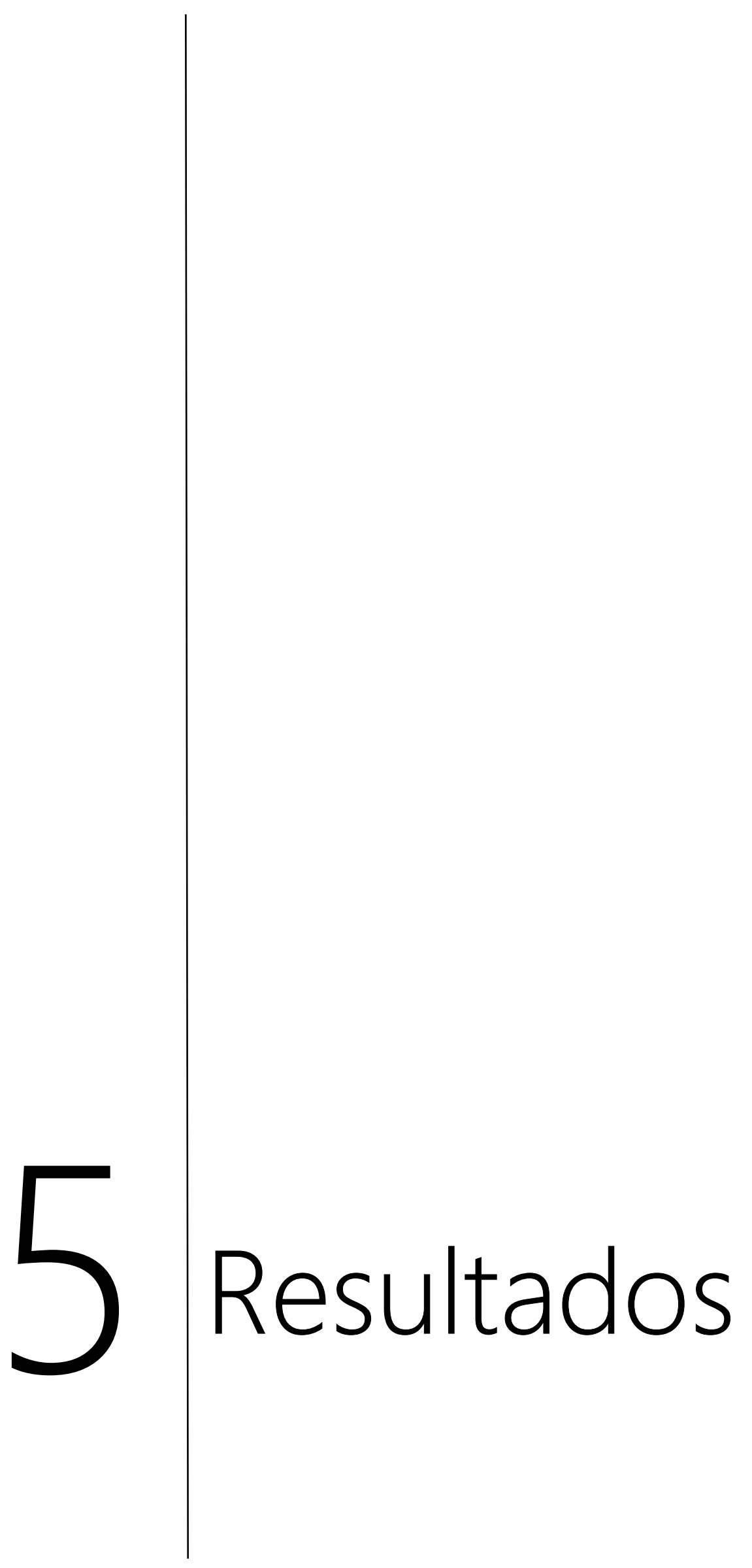





\section{RESULTADOS}

Para o presente estudo o erro intra-examinador foi maior que 0,8 presente na tabela 1 e a amostra não foi normal, desta forma foi utilizado o teste não paramétrico. Os valores da mediana mínimo e máximo podem ser observados na tabela 2.

Nos resultados da área mínima axial, todos os softwares apresentaram diferenças estatísticas significativas entre si. Com relação ao volume, houve diferença estatística significante também em todos os grupos, exceto entre o software in VIVO e ITK-Snap (para esta análise). 
Table 1. Intra-examinador

\begin{tabular}{ccc} 
& \multicolumn{2}{c}{ ICC (intra) } \\
\cline { 2 - 3 } Programa & $\begin{array}{c}\text { Área seccional mínima } \\
(\mathbf{m m})\end{array}$ & Vol (cm3) \\
\hline Dolphin3D & 0,96 & 0,96 \\
\hline InVivoDental & 1,00 & 0,98 \\
\hline InVesalius & 0,92 & 0,92 \\
\hline ITK-Snap & 0,81 & 0,98 \\
\hline NemoFAB & 1,00 & 0,96 \\
\hline ICC, coeficiente de correlação intraclasse
\end{tabular}


Table 2. Mediana (Med), minima e maxima (Min - Max) valores para área seccional mínima $\left(\mathrm{mm}^{2}\right)$ and $\mathrm{Vol}\left(\mathrm{cm}^{3}\right)$ segmentação com os 5 programas

\begin{tabular}{ccc} 
Grupos & Área seccional mínima $\left(\mathbf{m m}^{\mathbf{2}}\right)$ & Vol $\left(\mathbf{c m}^{3} \mathbf{)}\right.$ \\
\cline { 2 - 3 } & $\begin{array}{c}\text { Median } \\
(\text { Min-Max) }\end{array}$ & $\begin{array}{c}\text { Median } \\
(\text { Min-Max })\end{array}$ \\
\hline Dolphin3D & $\begin{array}{c}97,300^{\mathrm{a}} \\
(15,70-483,90)\end{array}$ & $\begin{array}{c}18,210^{\mathrm{A}} \\
(6,62-55,39)\end{array}$ \\
\hline InVivoDental & $75,550^{\mathrm{b}}$ & $15,850^{\mathrm{B}}$ \\
& $(16,60-442,80)$ & $(4,30-47,60)$ \\
\hline InVesalius & $163,420^{\mathrm{c}}$ & $16,540^{\mathrm{C}}$ \\
& $(58,89-645,39)$ & $(5,42-48,86)$ \\
\hline ITK-Snap & $140,685^{\mathrm{d}}$ & $15,140^{\mathrm{B}}$ \\
& $(39,59-517,14)$ & $(4,78-48,64)$ \\
\hline NemoFAB & $88,560^{\mathrm{e}}$ & $17,730^{\mathrm{D}}$ \\
& $(13,92-476,48)$ & $(4,96-51,53)$ \\
\hline Letras minúsculas diferentes na coluna indicam diferenças estatisticamente significativas entre os grupos $(\mathrm{P}<0,05)$. \\
Letras maiúsculas diferentes na coluna indicam diferenças estatisticamente significativas entre os grupos $(\mathrm{P}<0,05)$.
\end{tabular}





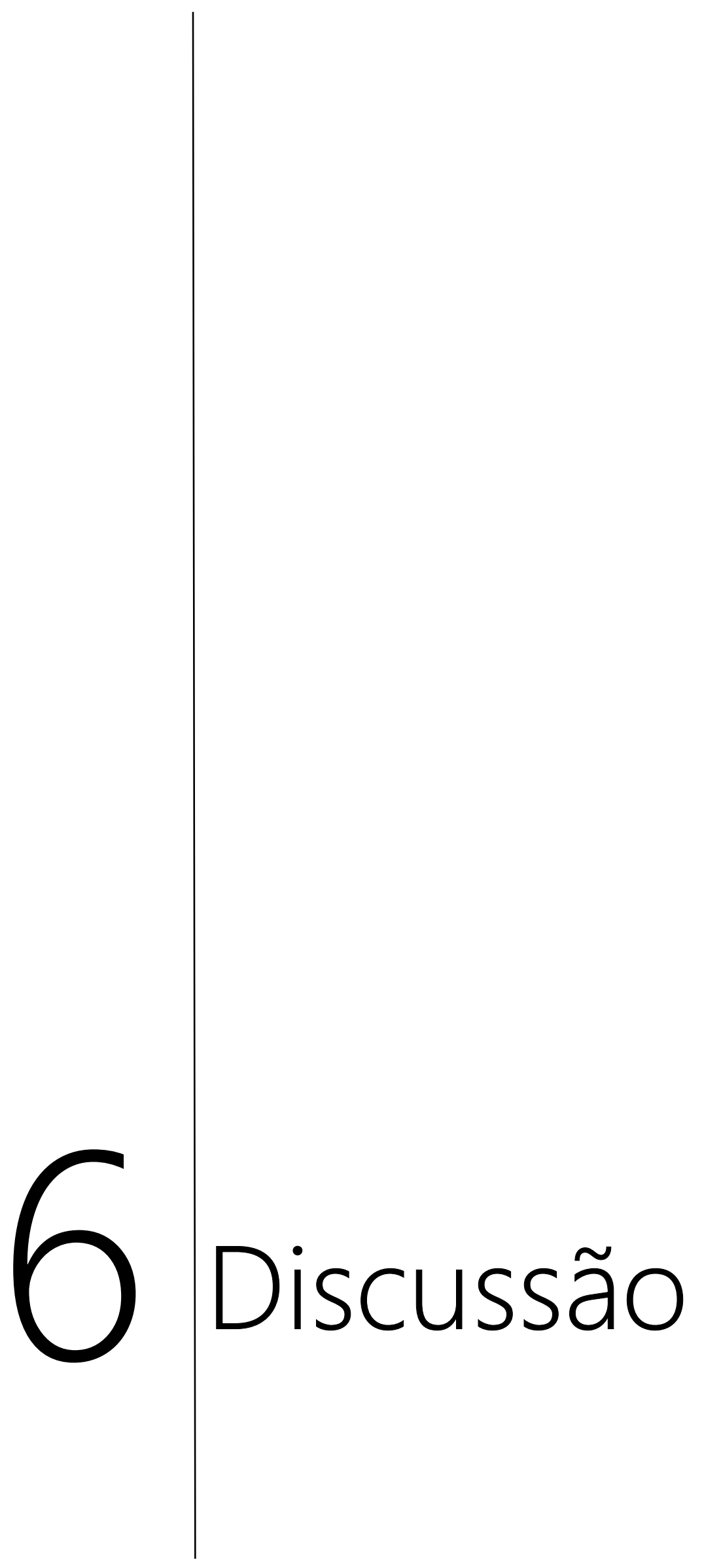





\section{DISCUSSÃO}

O presente estudo teve como objetivo comparar a medida do volume do espaço aéreo e a menor área axial da via aérea em cinco softwares de acesso livre ou pago, em pacientes com fissura labiopalatina, visando analisar a acurácia desses softwares. A partir de 100 TCFC os softwares foram avaliados por um examinador experiente e calibrado, e observou-se diferença estatisticamente significativa no volume da via aérea e da menor área axial em quase todos os programas, exceto entre o software InVivoDental e ITK-Snap.

Com o avanço do uso da TCFC, a avaliação das vias aéreas superiores pode ser realizada de forma eficaz e com ampla disponibilidade através de softwares, sendo que a literatura já descreveu 18 programas ou softwares em uma revisão sistemática (GUIJARRO-MARTÍNEZ e SWENNEN, 2011). Porém mais estudos são necessários com o intuito de comparar a precisão e confiabilidade de tais programas para análises de TCFC (PALOMO, 2010; WEISSHEIMER et al., 2012; PINHEIRO et al., 2018; KAMARUDDIN et al., 2019; TORRES et al., 2019), uma vez que novos sistemas surgem no mercado e descrevem apenas suas qualidades e possibilidades.

Para uma correta avaliação da via aérea superior, o processo de segmentação da imagem precisa ser realizado com exatidão e uma correta seleção da escala de níveis de cinza, propiciando melhor qualidade da imagem (WEISSHEIMER et al., 2012). As configurações do tomógrafo, gerenciamento e posicionamento na tomada radiográfica, bem como todo processo de reconstrução e exportação dos arquivos DICOM, são fatores que afetam diretamente a qualidade final do exame da TCFC (LIU et al., 2010). No presente estudo a TCFC foi realizada com o tomógrafo i-CAT, com configurações (Imaging Sciences International, Hatfield, PA, EUA), sob normas específicas rigidamente seguidas. Porém, alguns artefatos podem ser produzidos durante o exame tomográfico, o que influencia no processo de segmentação e sua precisão (WEISSHEIMER et al., 2012), mostrando viés e limitação do processo, pois alguns programas de imagens podem sofrer mais influência em relação aos demais.

De acordo com PALOMO (2010) a segmentação manual é um método que gera resultados mais precisos além de permitir maior controle por parte do operador. Porém é um processo lento, se tornando quase impraticável na prática clínica, necessitando de tempo hábil de 1 hora para cálculo do volume e área seccional 
mínima, enquanto os programas de segmentação automática precisam de apenas 5 minutos. Tais afirmações são observadas neste estudo nos programas de segmentação manual (ITK-Snap, InVesalius) onde houve um tempo maior para segmentação.

Este dado corrobora com o observado neste estudo. O programa ITK-Snap e o InVesalius foram os programas de maior autonomia do examinador na obtenção do volume e da área seccional mínima. Observou-se também que os valores de mediana do volume se mostrou mais próximo entre os programas de determinação automática e manual. Desta forma os resultados para a área seccional mínima ficaram na faixa de 70-100 nos programas de determinação do volume automático e na faixa de 140170 nos de determinação manual. É importante ressaltar que o ITK-Snap e o InVesalius, após a obtenção da segmentação do modelo 3D, a determinação da área seccional mínima obteve o mesmo processamento com a utilização do fatiador Slicer. $O$ fato de se mostrar diferente nestes grupos de programa pode estar relacionado com o algoritmo de obtenção da área seccional mínima, principalmente no que se refere ao parâmetro de cálculo. Nos programas manuais o fatiador faz a avaliação das áreas paralelas ao posicionamento da estrutura 3D segmentada, enquanto nos programas automáticos considera-se o posicionamento da tomografia, ou o fatiamento ser realizado perpendicularmente ao espaço aéreo. Estas informações não são disponibilizadas pelos fabricantes e a possibilidade sugerida, parte da observação dos examinadores na inclinação da área seccional mínima determinada pelo programa de forma automática. Vale ressaltar que todos os exames não foram reorientados e partiram do mesmo posicionamento que a imagem foi adquirida para que não houvesse o viés metodológico para a mudança de orientação da tomografia sendo que não é possível reorientar os modelos $3 \mathrm{D}$ em todos os programas utilizados.

Da mesma forma pode-se observar comportamento semelhante com os valores de volume e proximidades dos resultados entre o ITK-Snap, InVesalius e InVivoDental. Estes programas, embora o InVivoDental tenha a determinação do volume de forma automática ele apresenta uma diferença dos outros dois programas, pois sua obtenção não se dá pela seleção de uma área, mas sim pela determinação da trajetória da via aérea. Nos outros dois programas (ITK-Snap e InVesalius) a segmentação se dá pela determinação da área de interesse e posteriormente a localização e determinação da faixa de pixel selecionada. 
A segmentação de forma automática permite que as medidas de volume sejam feitas com método e cuidado mais adequado (EL PALOMO, 2010), e mostrou que a medição pode ser alterada de acordo com os limites escolhidos na imagem. Outros autores afirmaram que este tipo de segmentação é confiável e permite também a análise da área seccional mínima (CAMACHO, CAPASSO, 2014). No presente estudo essa segmentação foi utilizada nos softwares pagos, mas observamos que no Dolphin $3 \mathrm{D}$, o cálculo do volume não se mostra muito preciso, o que é também comprovado por outros estudos (TORRES et al., , 2019; WEISSHEIMER et al., , 2012)

Neste trabalho, cinco diferentes programas foram utilizados para avaliar 0 volume da orofaringe por meio de segmentação e construção de modelos virtuais 3D. Os cinco programas utilizam segmentação semiautomática e/ou automática, porém possuem diferentes ferramentas e mecanismos para segmentação das vias aéreas. Observa-se na literatura algumas divergências quanto a utilização de alguns programas, conforme descrito abaixo.

(1) Dolphin 3D: A segmentação das vias aéreas é realizada de forma objetiva, simples, rápida e permite a análise da área seccional mínima. A segmentação é realizada através da adição de pontos iniciais que se espalham e difundem pelo espaço pré estabelecido pela escala de níveis de cinza. O controle desta escala é realizado de forma precisa, e após determinado tal escala, a área é totalmente preenchida em todos os cortes (axial, sagital e coronal), porém neste processo de segmentação e preenchimento de tais espaços pode acontecer um exagero e ultrapassar os limites estabelecidos, principalmente em casos de via área morfologicamente complexa. Outro grande problema do Dolphin é que a escala de cinza é exibida em unidades próprias, diferentes e incompatíveis com aqueles softwares que utilizam a unidade Hounsfield. Observa-se a necessidade de atualização deste programa a fim de melhorar todo processo de segmentação, principalmente com a adequação das unidades da escala de cinza para serem compatíveis com os demais programas para análise de tomografias.

2) InVivo Dental: a análise das vias aéreas superiores pode ser realizada de forma simples e ágil. A região de interesse é delimitada através da escala de níveis de cinza, o que pode acarretar em uma limitação, pois não permite a revisão dos limites anatômicos e dificulta a averiguação da precisão da segmentação, o que pode ser observado em outro estudo. (WEISSHEIMER et al., 2012). 
3) ITK-Snap: é um programa disponível gratuitamente, porém, de difícil manuseio em comparação aos programas Dolphin3D, InVivo Dental e Nemocph. É ótimo para segmentação de modelos 3D. A segmentação é realizada de forma semiautomática utilizando a escala de cinza. Durante o preenchimento da área( voxels) pre estabelecidos pela escala de cinza, o programa apresenta boa sensibilidade, preenchendo inclusive áreas mais complexas. A utilização desse software bem como sua acurácia para segmentação foi descrita, validada e testada, (Yushkevich et al., 2006)

As superfícies do modelo tridimensional não sofrem suavização automática, fornecendo uma superfície mais real à segmentada, necessitando de refinamento para suavizar, se este for o objetivo. Gera informações de volume da tomografia e segmentação, porém necessita de outros softwares para obtenção da área seccional mínima, dessa forma, aumentando significantemente o tempo e a complexidade para obter outras informações. (PINHEIRO et al., 2018)

4) InVesalius: é um programa disponível gratuitamente, porém, de difícil manuseio em comparação aos programas Dolphin3D, InVivo Dental, Itk Snap e NemoFAB. Ele permite maior manejo ao pesquisador controle onde o usuário pode "esculpir" o volume desejado das vias aéreas do resto das estruturas 3D e, ajustando os valores de brilho e opacidade, limpar os voxels indesejados antes de calcular o volume final das vias aéreas. O programa também permite que o usuário altere os valores limite (faixa de valores de densidade exibidos) para obter um volume sólido das vias aéreas.

5)NemoFAB: é um programa pago, porém de fácil manuseio, onde o operador delimita a área de interesse através da demarcação de alguns pontos e marcação de ponto dentro da imagem demarcada fazendo com que o programa sublinhe a área demarcada. Após a delimitação do espaço aéreo teremos como resultado o volume da via aérea bem como a área seccional mínima.(ALCALDE et al., 2019)

A análise do volume da via aérea superior é dependente de uma correta segmentação e sua acurácia deve ser confiável. Porém esta tem direta relação com a aquisição da TCFC e a seleção da escada de cinza. Uma imagem de boa qualidade só é conseguida com um tomógrafo que apresente corretas configurações, bem como experiência do radiologista no processo de posição do paciente, volume da reconstrução, tamanho do voxel e forma de exportação do arquivo DICOM (WEISSHEIMER et al., , 2012). Alguns trabalhos demonstram também que a 
qualidade das imagens podem sofrer influência da média de densidade dos voxels, ruídos e artefatos que afetam a densidade tecidual (SCHULZE et al., , 2011; BARRETT , 2004; MAH et al., , 2010).

A TCFC não respeita o padrão de utilização da unidade Hounsfield (HU), seus valores são influenciados pelo tipo de dispositivo, forma da aquisição da imagem, bem como posicionamento do paciente, (NACKAERTS et al., 2011), observando também outros estudos que não validaram o uso de HU em TCFC (SILVA et al., 2012; Yamashina $A$ et al 2008), com isto observa se poucos estudos na literatura que validaram o uso de HU em TCFC, sem uso de qualquer fator de correção ou equação de conversão Valiyaparambil JV., 2012. Em 2012 um estudo sugere uma avaliação mais criteriosa da TCFC, pois os valores dos coeficientes de Hounsfield se mostraram mais elevados na TCFC, em comparação com a multislice (SILVA et al., 2012). Tais fatores sugerem influência nos resultados tão discrepantes em nossa pesquisa.

Considerando os resultados estatísticos encontrados no presente trabalho a hipótese nula primária foi rejeitada. Houve grande limitação na análise do volume e menor área axial da via aérea, o que corrobora em muito nesse resultado, visto que tal avaliação é dependente de uma correta segmentação das TCFC nos programas apresentados, o que também pode ser observado na literatura (WEISSHEIMER et al.,2012). Foi constatado pela aplicação desta metodologia que houve discrepância de até $16 \%$ na aferição do volume das mesmas imagens e até $53 \%$ da área seccional mínima. Isto ocorre mudando apenas o software utilizado.

Observa-se também uma maior complexidade para se obter o valor e posição da área seccional mínima com os softwares de código aberto ITK-SNAP e Invesalius + módulo SPHARM-PDM em relação ao software Dolphin3D e o InVivo. 



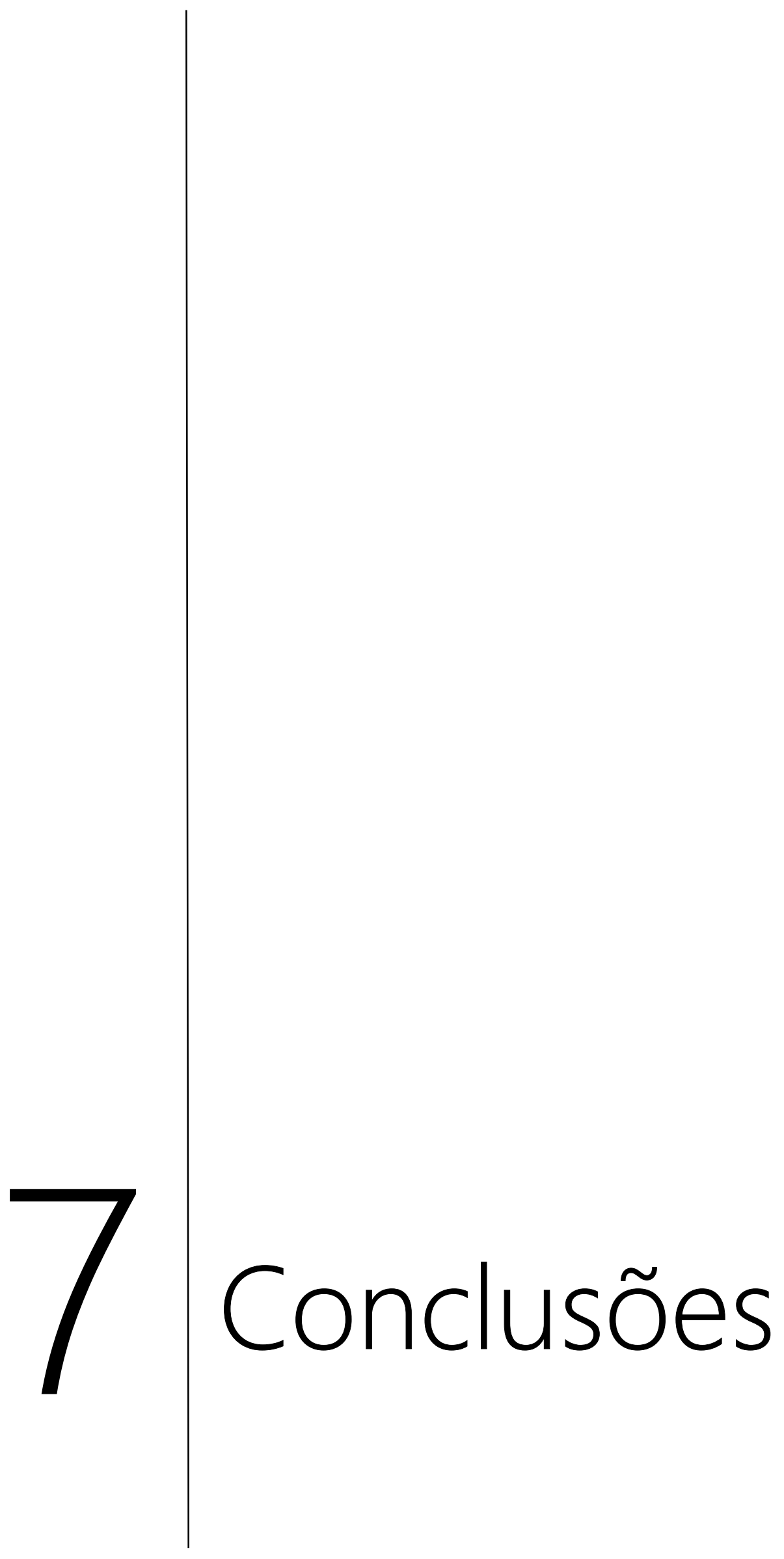





\section{CONCLUSÕES}

Nos resultados da área mínima axial, todos os cinco programas apresentaram diferenças estatísticas significativas entre si. Com relação ao volume, houve diferença estatística significativa também em todos os grupos, exceto entre o software in VIVO e ITK-Snap (para esta análise).

O uso de HU na TCFC parece exercer forte influência sobre os resultados, sugerindo então mais estudos para tal questão, bem como uso de softwares que possam realizar conversão de tais valores de forma precisa.

A comparação de acompanhamento entre pré e pós tratamento deve ser realizada com o mesmo software. 

Referências 



\section{REFERÊNCIAS}

ABOUDARA, C. et al., Comparison of airway space with conventional lateral headfilms and 3-dimensional reconstruction from cone-beam computed tomography. American Journal of Orthodontics and Dentofacial Orthopedics, v. 135, n. 4, p. 468479, 2009.

CAMPOS, M. J. D. S. et al. The role of orthodontic tooth movement in bone and root mineral density: A study of patients submitted and not submitted to orthodontic treatment. Medical Science Monitor, v. 18, n. 12, 2012.

CASSETTA, M. et al. How Accurate Is CBCT in Measuring Bone Density? A Comparative CBCT-CT In Vitro Study. Clinical Implant Dentistry and Related Research, v. 16, n. 4, p. 471-478, 2013.

Computer reconstructed X-ray imaging. Philosophical Transactions of the Royal Society of London. Series A, Mathematical and Physical Sciences, v. 292, n. 1390, p. 223-232, 1979.

EL, H.; PALOMO, J. M. Measuring the airway in 3 dimensions: A reliability and accuracy study. American Journal of Orthodontics and Dentofacial Orthopedics, v. 137, n. 4, 2010.

GUIJARRO-MARTÍNEZ, R.; SWENNEN, G. Cone-beam computerized tomography imaging and analysis of the upper airway: a systematic review of the literature. International Journal of Oral and Maxillofacial Surgery, v. 40, n. 11, p. 1227-1237, 2011.

HAN, S. et al., Evaluation of palatal bone density in adults and adolescents for application of skeletal anchorage devices. The Angle Orthodontist, v. 82, n. 4, p. 625-631, 2012.

HOUNSFIELD, G. N. Computerized transverse axial scanning (tomography): Part 1. Description of system. The British Journal of Radiology, v. 46, n. 552, p. 1016-1022, 1973.

ISABELA MARIA DE CARVALHO CRUSOÉ SILVA et al. Bone density: comparative evaluation of Hounsfield units in multislice and cone-beam computed tomography. Brazilian Oral Research, v. 26, n. 6, p. 550-556, 2012.

ISODA, K. et al., Relationship between the bone density estimated by cone-beam computed tomography and the primary stability of dental implants. Clinical Oral Implants Research, v. 23, n. 7, p. 832-836, 2011.

JONES, E. M.; PAPIO, M.; TEE, B. C; BECK, F. M.; FIELDS, H. W.; SUN, Z. Comparison of cone-beam computed tomography with multislice computed tomography in detection of small osseous condylar defects. Am J Orthod Dentofacial Orthop, St. Louis, v. 150, n. 1, p. 130-139, Jul. 2016. 
KIEMLE, T.-S. I. et al., Tomographic Pharyngeal Dimensions in Individuals with Unilateral Cleft Lip/Palate and Class III Malocclusion are Reduced When Compared with Controls. The Cleft Palate-Craniofacial Journal, v. 54, n. 5, p. 502-508, 2017.

KIM, Y.-J. et al.Three-dimensional analysis of pharyngeal airway in preadolescent children with different anteroposterior skeletal patterns. American Journal of Orthodontics and Dentofacial Orthopedics, v. 137, n. 3, 2010.

$\mathrm{KIM}, \mathrm{H}$.-S. et al. Three-dimensional evaluation of the pharyngeal airway using conebeam computed tomography following bimaxillary orthognathic surgery in skeletal class III patients. Clinical Oral Investigations, v. 20, n. 5, p. 915-922, 2015

LACERDA, R. H. W. et al. Facial growth evaluation of complete unilateral cleft lip and palate operated patients: a cleft reference center in Paraíba, Brazil, using the "GOSLON" yardstick. Oral and Maxillofacial Surgery, v. 18, n. 4, p. 403-407, 2013.

LENZA, M. et al. An analysis of different approaches to the assessment of upper airway morphology: a CBCT study. Orthodontics \& Craniofacial Research, v. 13, n. 2, p. 96-105, 2010.

MCCOMB, R. W. et al. Predictors of Velopharyngeal Insufficiency After Le Fort I Maxillary Advancement in Patients With Cleft Palate. Journal of Oral and Maxillofacial Surgery, v. 69, n. 8, p. 2226-2232, 2011.

OGAWA, T. et al. Evaluation of cross-section airway configuration of obstructive sleep apnea. Oral Surgery, Oral Medicine, Oral Pathology, Oral Radiology, and Endodontology, v. 103, n. 1, p. 102-108, 2007.

OZAWA, T. O. et al.A New Yardstick for Rating Dental Arch Relationship in Patients with Complete Bilateral Cleft Lip and Palate. The Cleft Palate-Craniofacial Journal, v. 48, n. 2, p. 167-172, 2011.

PINHEIRO, M. L. et al., Volumetric reconstruction and determination of minimum crosssectional area of the pharynx in patients with cleft lip and palate: comparison between two different softwares. Journal of Applied Oral Science, v. 26, 2018.

POSNICK, J. C.; RICALDE, P. Cleft-orthognathic surgery. Clinics in Plastic Surgery, v. 31, n. 2, p. 315-330, 2004.

SCHENDEL, S. A.; HATCHER, D. Automated 3-Dimensional Airway Analysis From Cone-Beam Computed Tomography Data. Journal of Oral and Maxillofacial Surgery, v. 68, n. 3, p. 696-701, 2010.

SCHNEIDER, D.; KÄMMERER, P. W.; SCHÖN, G.; BSCHORER, R. et al. A threedimensional comparison of the pharyngeal airway after mandibular distraction osteogenesis and bilateral sagittal split osteotomy. J Craniomaxillofac Surg, Stuttgart, v. 43 , n. 8 , p. 1632-1637, Oct. 2015. 
TORRES, H. M. D. et al. Comparison of Dimensions of the Nasopharynx and Oropharynx Using Different Anatomical References: Is There Equivalence? Journal of Oral and Maxillofacial Surgery, v. 77, n. 12, p. 2545-2554, 2019.

WALLACE, S. C.; PIKOS, M. A.; PRASAD, H. De novo Bone Regeneration in Human Extraction Sites Using Recombinant Human Bone Morphogenetic Protein-2/ACS. Implant Dentistry, v. 23, n. 2, p. 132-137, 2014.

WEISSHEIMER, A. et al., Imaging software accuracy for 3-dimensional analysis of the upper airway. American Journal of Orthodontics and Dentofacial Orthopedics, v. 142, n. 6, p. 801-813, 2012.

YAMASHINA, A. et al., The reliability of computed tomography (CT) values and dimensional measurements of the oropharyngeal region using cone beam CT: comparison with multidetector CT. Dentomaxillofacial Radiology, v. 37, n. 5, p. 245251, 2008.

YATABE-IOSHIDA, M. S. et al., Upper Airway 3D Changes of Patients With Cleft Lip and Palate After Orthognathic Surgery. The Cleft Palate-Craniofacial Journal, v. 56, n. 3, p. 314-320, 2018.

YUSHKEVICH, P. A. et al., User-guided 3D active contour segmentation of anatomical structures: Significantly improved efficiency and reliability. Neurolmage, $v$. 31, n. 3, p. 1116-1128, 2006. 

Anexo(s) 

ANEXO A - COMITÊ DE ÉTICA E PESQUISA

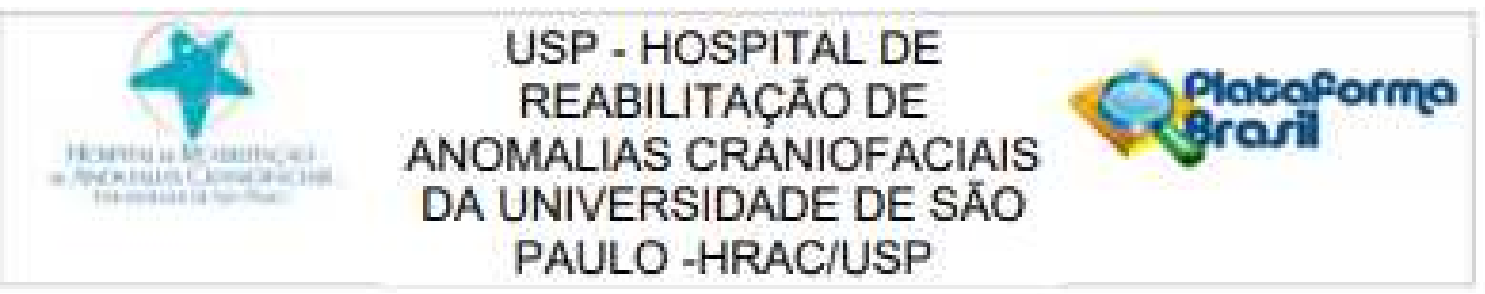

\section{PARECER CONSUBSTANCIADO DO CEP}

\section{DADOS DO PROJETO DE PESQUISA}

Titulo da Pesquisa: Avaliaçáo da acuracio de programas de mensuraçầo do volume do espsç̧o ațreo e da áres avial minima em pacienles com fissura labiopasalina

Pesquisador: Simone Soares

Aroa Temática:

Versāo: 1

CAAE: 20593219.4 .00005441

Instituiçâo Proponente: Hospital de Reabitlaçato de Anomalias Craniofaciais da USP

Patrocinador Principal: Financiamento Próptio

\section{DADOS DO PARECER}

Nümero do Parecer: 3.605 .233

Apresentaçâo do Projeto:

Projeto de pesquisa para Disserfaçầ na àrea de Cirutgia Bucomaxilolacial. Estudo transversal de comparaçào de softwares para avaliar o volume do espaço aéreo e a menor área axial. $O$ objetivo do trabatho é comparar a medida do volume do espaço aéreo e a menor área axial da vá aèrea em pacientes com fissura labiapalatina por meio de 5 diferentes softwares de imagem: Dolphin $3 D$, NemoCeph, inViva Dentai, ITK Snap e InVesalius para anślise tridimensional da wa aérea, atraves de imagens de TCFC Inicialmente, um examinador selecionard 100 tomografias compuladorizadas do lipo feixe cónico, sendo coletado seu arquivo DICOM. As segmentaçobes da bucofaringe seräo realizadas de acordo com as referências do fabcicante. $\mathrm{Os}$ resultados serb́ submetidos a um leste de andlise de variancia (ANOVA) para comparar os resultados obtidos do volume das vias aereas das tomografias na lentatha de avaliar se existe diferença significativa entre eles. Será adotado o nivel de signalicalncia de $5 \%$ para todos as testes estatisticos. Dessa forma, com esta pesquisa espera-se resultados que validam, com maiores detalhes, a sourácia de soltwares para analise das vias aereas, legifimando, assim, estudos que avaliam o aumento de vias aéreas superiores em pacientes com fissura labiapalatina, submetidos a crurgia orfognatica.

\section{Objetivo da Pesquisa:}

O objetivo deste trabaho e comparar a medida do volume do espap̧o aéreo e da menar área axial

Endereçe: Rue Bivio Marcheare 3-20

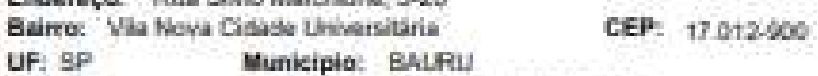

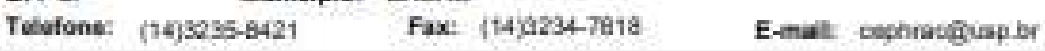




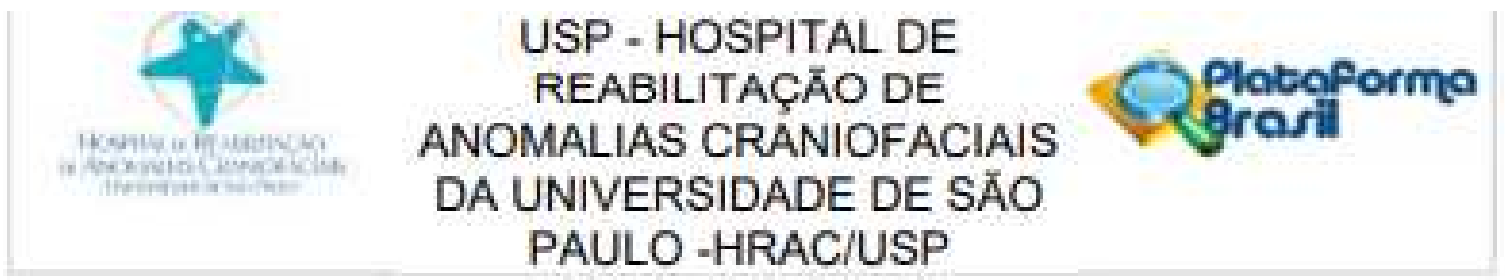

Contruacto do Nawar 3 eas 23

da via aèrea em pacienles com fissura labiopalatina por meio de cinco programas para avaliaçào da via aèrea.

\section{Avaliaçào dos Riscos e Beneficios:}

Segundo as antores:

"Risoos:

Nenhum risco, uma vez que as tomografias jä foram realizadas e serbo avaliadas e mensuradas.

Beneficios:

Com a crescente nùmero de pesquisa envolvendo a mensuraçalo da via aérea, hà nectessidade de trabalhos que validam programas para este fim. Sendo assim os resullados desta pesquisa podem contribuit para o teste de precisaso e acurbcia de alguns dos principais soltwares de imagem que estäo disponiveis para odontologia."

\section{Comentários e Consideraçōes sobre a Pesquisa:}

Pesquisa transversal de comparaçào de softwares para avalat o volime do espaço aéreo e da menor área axial, apresenta menț e estă bem estruturada. Para a fealizaçăo do presente estudo serảo obtidos do prontuário do paciente, dados como: o sexo, idade e classificaçăo da fissura, presença au ausência de sindrome e a bamografia computadorizada feixe cônico (TCFC) A pesquisa utilizará 100 TCFC de pacientes com fissura labiopalatina transforame incisivo unilateral do arquivo de imagens do Hospital de Reabilitapalo de Anomalias Craniofaciais. A partir das TCFC seráo selecionados, de forma aleatbiria, as imagens que serào objeto de andlise. Com o intuito de delerminar o volume da bucofaringe, sera criatos modeios volumétricos tridimensionais, as quais serbo teconstruidos e meneurados pelos soltwares de imagem. Com isto as referencias anatêmicas para segrnentaçb̆o da bucolaringe serb̆o: borda ântero- rflerior da vértebra quarta cervical (C4), borda inferior-postesice do asso hioide, parede faringea anterioe e basal, formando um retângulo.

\section{Consideraçōos sobre os Termos de apresentaçbōo obrigatória:}

Carts de encarninhamento;

Formulário HRAC:

Folha de Rosto da Plataforma Brasit;

Justificativa de Dispensa de TCLE:Terma de Compromisso, Confidencialidade e Autorizaçăo de Utilização de Dados em Projesos de Pesquisa

Termo de Campramisso de Tornar Pútlicos us Resullados da Pesquisa e Destinaçăo de Materias

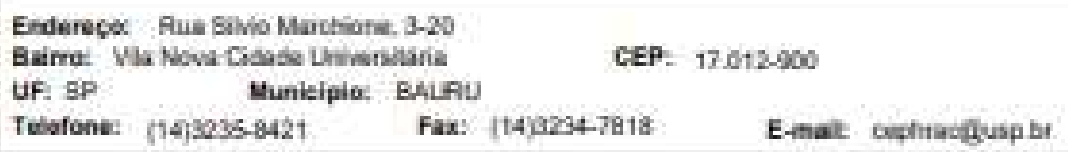




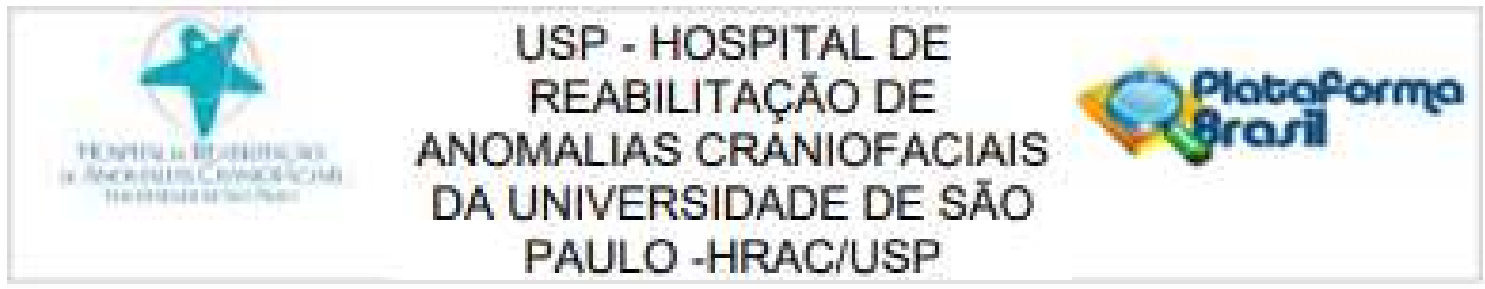

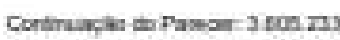

ou Dados Coletados:

Temo de Compromisso do Pesquisador Responsavel.

TERMO DE PERMISSAO PARA USO DE REGISTROS PARA FINS CIENTIFICOS

\section{Recomendaçồes:}

Nấo se aplica.

\section{Conclusōes ou Pendênelas o Lista de Inadequaçōes:}

Cono o projeta nâo fere aspectos èticos, sugiro sua aprowaçẫo.

\section{Consideraçōes Finais a critterio do CEP:}

$O$ pesquisador deve atentar que a projeto de pesquisa aprovado por este CEP refere-se ao protocolo submetido para avaliaçăo. Portanto, conforme a Resoluçăo CNS 466/12, a pesquisador è responsàvel por "desenvolver o projelo conforme delineado", se caso houver alteraçoses nesse projeto, este CEP devera ser comunicado en emenda via Plataforma Brasê, para nova avalisçăo.

Cabe as pesquisador notificar via Platalorma Brasil a relatório final para avaliaça.o. Os Termos de Consentimento Livre e Esclarecidos elou outros Termos obrigatórios assinados pelos participantes da pesquisa deverato ser entregues ao CEP. Os relatórios semestrais devem ser notificados quando solicitados no parecer.

Este parecer fol elaborado baseado nos documentos abaixo rolacionados:

\begin{tabular}{|c|c|c|c|c|}
\hline Tipo Documento & Arquivo & Postagem & Autor & Situaçào \\
\hline Outros & Checklist_Prot_Pesq_82_2019.pdf & $\begin{array}{c}11 / 00 / 2019 \\
17.33: 22\end{array}$ & $\begin{array}{l}\text { Rafael Mattos de } \\
\text { Deus }\end{array}$ & Aceito \\
\hline $\begin{array}{l}\text { Informaçóes Básicats } \\
\text { do Proieto }\end{array}$ & $\begin{array}{l}\text { PB_INFORMACOES_BASICAS_DO_P } \\
\text { ROOJETO 1421920.pdf }\end{array}$ & $\begin{array}{c}10 \times 109 / 2019 \\
1728.46\end{array}$ & & Aceilia \\
\hline $\begin{array}{l}\text { Projeto Detaliado I } \\
\text { Brochura } \\
\text { Investiander }\end{array}$ & projetobeethoven.pdi & $\begin{array}{l}\text { T0109:2079 } \\
17: 10: 37\end{array}$ & Simone Sodres & Aceiso \\
\hline Outros & $\begin{array}{l}\text { lemodecompromissodopesquisadortesf } \\
\text { onsave odf }\end{array}$ & $\begin{array}{c}1000 / 2019 \\
17.07 .51\end{array}$ & Simone Subres & Aceito \\
\hline Oç̧amento & creamento docx & $\begin{array}{c}06 / 09 / 2019 \\
11: 28: 33\end{array}$ & Simone Sodres & Aceilo \\
\hline Cronograma & CRONOGRAMA DOCX & $\begin{array}{l}06109 / 2019 \\
11: 27: 30\end{array}$ & Simone Soares & Aceilo \\
\hline Outros & termpermiusoregistro pol & $\begin{array}{c}06 / 09 / 2019 \\
11: 19.50\end{array}$ & Simone Sosares & Aceila \\
\hline
\end{tabular}

Endereçe. Rus Sivio Marchiane, 3-20

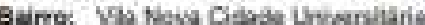
UF: IP Munieipiar: BLRU

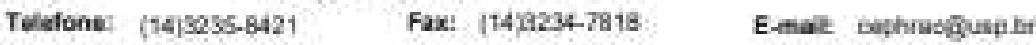




\section{USP - HOSPITAL DE \\ REABILITAÇÄO DE ANOMALIAS CRANIOFACIAIS \\ DA UNIVERSIDADE DE SÄO \\ PAULO - HRAC/USP}

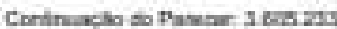

\begin{tabular}{|c|c|c|c|c|}
\hline Oubos & leimoompconfautdados.pdf & $\begin{array}{c}06092019 \\
11: 18.24\end{array}$ & Simone Soares & Aceilo \\
\hline Outros & termcomptomarpubicodesimat.pdt & $\begin{array}{l}060902019 \\
11: 16: 31\end{array}$ & Simone Sosires & Acelo \\
\hline $\begin{array}{l}\text { Dedaraçalo de } \\
\text { Pesquisadores }\end{array}$ & cartsencamininamento,pdf & $\begin{array}{c}06109 / 2019 \\
11: 11: 37\end{array}$ & Simone: Sosares & Aceito \\
\hline $\begin{array}{l}\text { TCLE / Termos de } \\
\text { Assentimento / } \\
\text { Justificativa de } \\
\text { Ausencia }\end{array}$ & justificalivadispensatcle.pdl & $\begin{array}{l}06 / 09 / 2019 \\
11: 10.43\end{array}$ & Simone: Soares & Aceilo \\
\hline $\begin{array}{l}\text { Dedaraçato de } \\
\text { instiluiçaso e } \\
\text { infrategintutara }\end{array}$ & formeadastrohrac.pdt & $\begin{array}{l}\text { D6/DQ/2019 } \\
11: 09: 07\end{array}$ & Simbne Scares & Acello \\
\hline Folna de Rosto & foharcsto.pdl & $\begin{array}{c}0609 / 2019 \\
11: 08: 23\end{array}$ & Simone: Soares & Aceilo \\
\hline
\end{tabular}

Situação do Parecer:

Aprowado

Nocessita Apreciaçào da CONEP:

Naso

BAURU, 27 de Seternbro de 2019

Assinado por:

Silvia Maria Graziadei

[Coordenador(a)]

Endereçe Rua Bivio Marchiant, 3-20

Beirre: Via Nava Ciasde Universitaria

UF: GP Municipio: BALRL

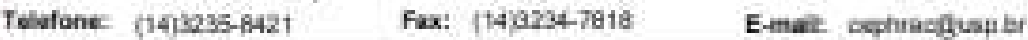

